\title{
A Framework for Classifying Participant Motivation that Considers the Typology of Citizen Science Projects
}

\author{
Maryam Lotfian ${ }^{1,2, * \mathbb{D}}$, Jens Ingensand ${ }^{1}$ and Maria Antonia Brovelli ${ }^{2} \mathbb{C}$ \\ 1 Institute INSIT, School of Business and Engineering, University of Applied Sciences and Arts, \\ 1401 Yverdon-les-Bains, Switzerland; jens.ingensand@heig-vd.ch \\ 2 Department of Civil and Environmental Engineering, Politecnico di Milano, Piazza Leonardo da Vinci 32, \\ 20133 Milano, Italy; maria.brovelli@polimi.it \\ * Correspondence: maryam.lotfian@polimi.it
}

Received: 8 October 2020; Accepted: 22 November 2020; Published: 25 November 2020

check for updates

\begin{abstract}
Citizen science, the participation of the public in scientific projects, is growing significantly, especially with technological developments in recent years. Volunteers are the heart of citizen science projects; therefore, understanding their motivation and how to sustain their participation is the key to success in any citizen science project. Studies on participants of citizen science projects illustrate that there is an association between participant motivation and the type of contribution to projects. Thus, in this paper, we define a motivational framework, which classifies participant motivation taking into account the typologies of citizen science projects. Within this framework, we also take into account the importance of motivation in initiating and sustaining participation. This framework helps citizen science practitioners to have comprehensive knowledge about potential motivational factors that can be used to recruit participants, as well as sustaining participation in their projects.
\end{abstract}

Keywords: motivation; citizen science; participation inequality; volunteered geographic information; online citizen science; classic citizen science

\section{Introduction}

Citizen Science (CS) — the participation of members of the public in scientific projects [1] —has grown significantly in recent years, specifically because of developments in mobile technology [2]. Due to the introduction of new knowledge production models and expanding participation in science, CS is usually seen as one of the subactivities of the open science concept [3]. Initially, CS focused primarily on ecological and environmental sciences [4-6], but has expanded over time to several scientific fields, resulting in hundreds of mobile or web-based CS applications [7] in areas such as astronomy [8], biology [9], medicine [10], etc. Public participation in scientific projects is beneficial for both volunteers and scientists, as on one hand, scientists are able obtain information that is difficult to access or expensive [11,12], and, on the other hand, volunteers not only acquire scientific knowledge, but also learn about the scientific procedures conducted within a research group [2].

Volunteered Geographic Information (VGI), a term coined by Goodchild [13], describes the participation of a large number of individuals in the creation of geographic information. VGI and CS projects intersect when CS participation includes collecting or analysing geographic information; Haklay referred to this intersection as Geographic Citizen Science [14]. A large number of CS projects are part of VGI, and CS and VGI mostly share common issues and challenges in creating and maintaining successful projects.

The key challenges for a successful CS and VGI project are first looking for ways to attract volunteers and then assessing the quality of data collected by them [15]. While a large number of 
researchers in CS projects are concerned about the quality of collected data by nonprofessionals or citizen scientists [16-19], not as many studies have focused on the volunteers themselves [20,21]. Volunteers are the heart of CS projects; therefore, understanding how to recruit them and how to sustain their participation is of utmost importance [22-24]. In recent years, however, the number of publications seeking to understand the motivation of participants in CS initiatives has grown, suggesting that researchers are paying a lot more attention to the importance of recruiting volunteers and keeping them active in the project. Most of these studies conducted a questionnaire or interview to identify the main motivational factors for the participants in their projects [25-28]. Given the existence of several motivational studies on CS use cases, there is still a shortage of more comprehensive findings from such research in the CS area [29].

CS projects can be categorised according to the project structure and activities to be carried out by volunteers, such as the formulation of hypotheses, problem definition, data collection, analysis of results, etc. [1,14]. Although the motivational factors differ from project to project, projects that share the same typology and similar goals and outlines appear to have common elements to influence volunteers to participate and keep them involved [30]. Another factor that triggers variation in motivation is that people participate differently when it comes to voluntary activities, i.e. motivation for initial participation in CS projects differs from that for the long term [20].

Accordingly, bearing in mind the above elements, it is important to get a more comprehensive view of the motivation of participants in order to properly grasp how to sustain a successful CS project. Curtis [30] has studied participant motivation for online CS projects but, to the best of our knowledge, no research has established a thorough classification system for motivational variables for all forms of CS projects. For this reason, the aim of this article is to categorise the motivation of volunteers, taking into account the typology of CS projects as well as the importance of motivation as rated by volunteers. To do so, a literature review was performed with the goal of first identifying different types of CS and then extracting the motivational factors from studies carried out using volunteers for each CS use case. We established a framework as a result of this literature review, which classifies motivation depending on both the typologies of CS projects and the strength of the motivation for initiating and sustaining participation. Finally, as a preliminary discussion of the framework, we present the results of an online survey that we conducted to identify the motivation of potential participants to contribute to our Biodiversity CS project, BioPocket.

This paper is structured as follows: the following section presents the concept of participation patterns in online communities, VGI and CS projects. The typologies of CS projects are discussed in Section 3, followed by a presentation of the motivational factors commonly identified for voluntary activities and VGI projects in Section 4. In Section 5, we reviewed the CS use cases and extracted the motivational factors identified in each study. The motivational framework is discussed in Section 6, and the results of our BioPocket survey are presented in Section 7. Finally, the conclusions and future perspectives of the framework are discussed in Section 8.

\section{Participation Patterns}

"All large-scale, multi-user communities and online social networks that rely on users to contribute content or build services share one property: most users don't participate very much. Often, they simply lurk in the background." [31].

According to Nielsen [31], the concept of participation inequality was first introduced by Will Hill [32]; this term refers to the fact that the majority of content in online forums is generated by a minority of volunteers, while the majority of people are simply using the generated information. User participation usually follows 90-9-1 rule [31,33], implying that 1 per cent of the users participate very frequently, 9 per cent of the users participate "from time to time", and 90 per cent of the users are "lurkers", indicating that they only read or observe information without contributing. Although some projects have hundreds of registered participants, only a few of them actively make contributions [30]. Preece and Shneiderman [34] analysed the patterns of contributions to online communities and 
social networks such as YouTube or Wikipedia and, as a result, developed a framework called "Reader-to-Leader", showing the evolution of user participation in online social communities from readers, to contributors, collaborators, and ultimately leaders (Figure 1).

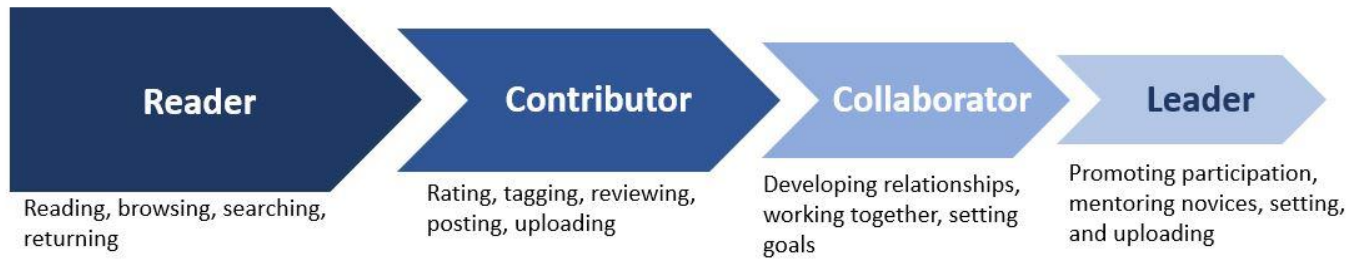

Figure 1. The "Reader-to-leader" framework adapted from Preece and Shneiderman [34], which illustrates the pattern of participant evolution in online social media communities. The sizes of the arrows illustrate the number of users. The number of users from reader to leader decreases in each category, meaning that the minority of users contribute the majority of contents.

In addition, we can mention OpenStreetMap (www.openstreetmap.org), as a well-known VGI project where participation inequality among volunteers has been discussed several times $[35,36]$. Wood's analysis [37] illustrated that only a small number of participants among the registered users (about 150,000 out of 2 million registered users at the time of analysis) contribute more than 100 points of data (Figure 2). This pattern has persisted until now, since OpenStreetMap statistics show that only $1 \%$ of all users contribute regularly [38]. Wood also noted that it is essential to understand how to recruit new participants, and to encourage registered participants to contribute (make edits) and active participants to continue with their contributions (Figure 3).

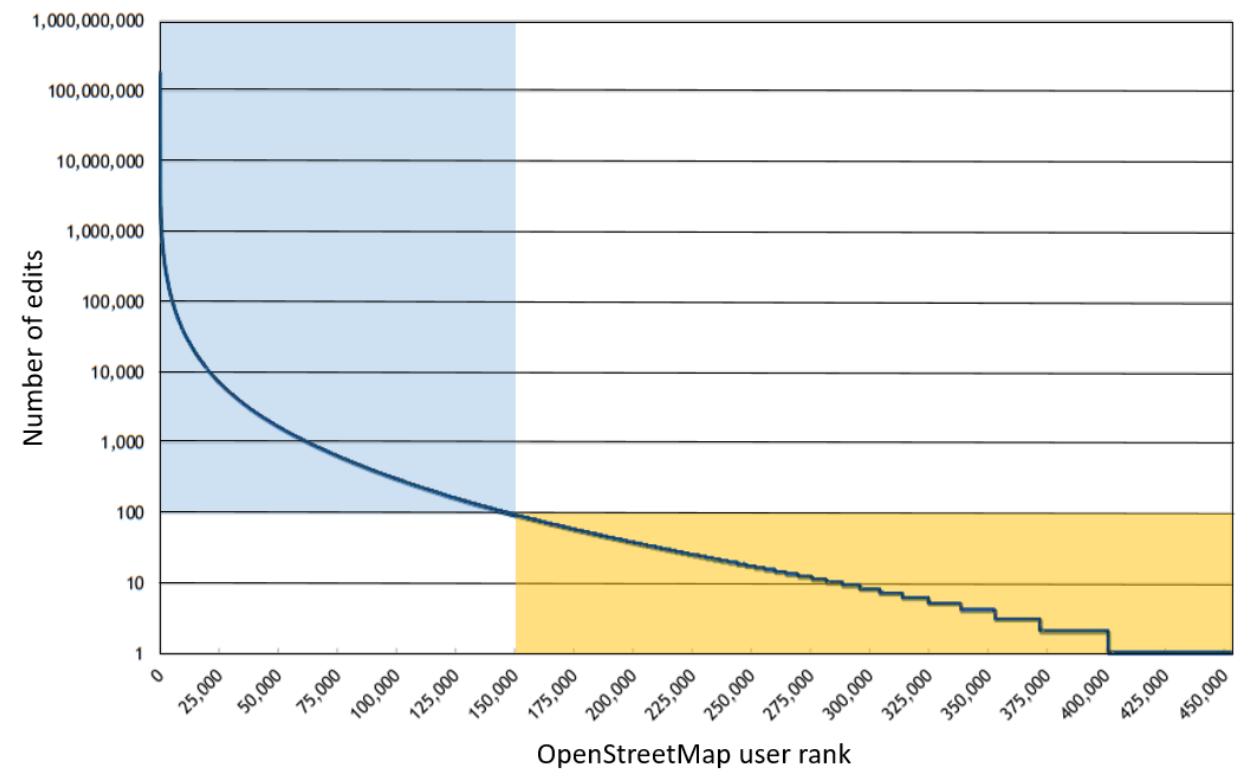

Figure 2. Participation inequality in OpenStreetMap adapted from Wood's analysis [37]. The figure shows the number of users that contributed at least one edit. It illustrates that most of the contributions are performed by a small number of users. Only about 150,000 users (out of 2 million registered users at the time of analysis) contributed more than 100 points of data (blue side); the remaining users collectively contributed less than 100 edits (orange side). 


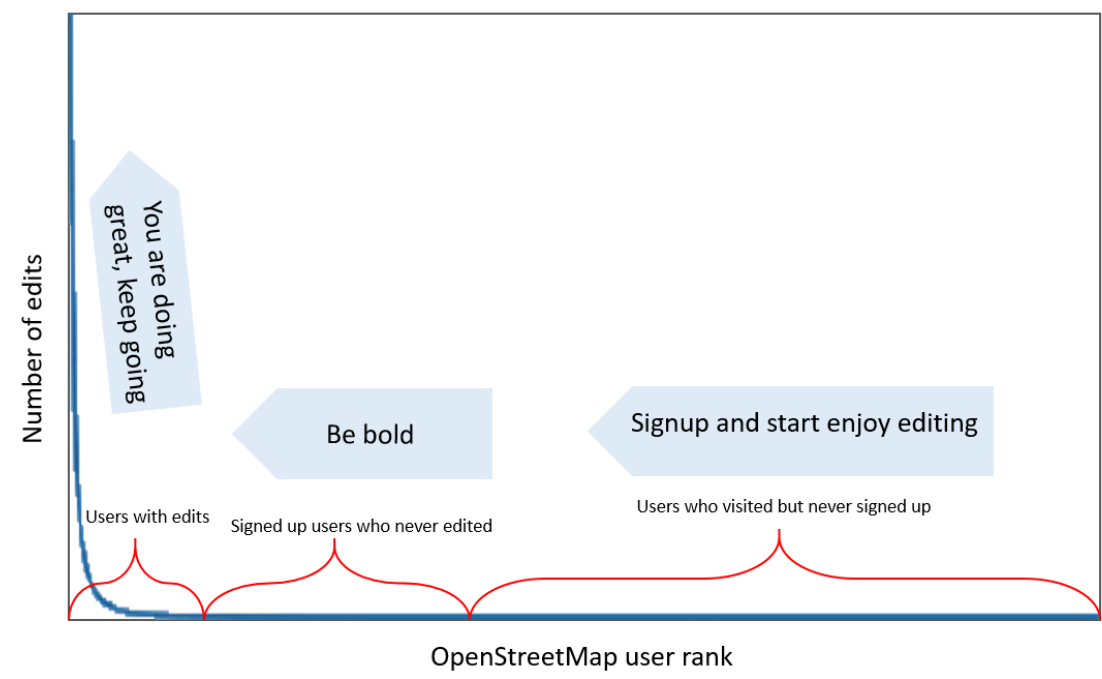

OSM is awesome, come and visit

Figure 3. How to encourage users to contribute to OpenStreetMap? Adapted from Wood's analysis [37]. The figure shows the need to use various ways to motivate each group of potential volunteers to contribute to OpenStreetMap. The steps (from right to left) include encouraging people to visit OpenStreetMap, then encouraging them to sign up and make contributions, and finally, to keep the active contributors motivated and engaged.

In addition, Budhathoki and Haythornthwaite [39] classified OpenStreetMap participants into serious and casual mappers, taking into consideration the amount of their contribution (number of contributed nodes), the duration of contribution, and the frequency of contribution. The survey results of the motivations of these two classes of OpenStreetMap participants illustrated that serious mappers were more driven by a desire to be part of a community, and by learning and career-based factors, whilst for casual mappers, the thought of creating free and accessible maps for others was a stronger motivational factor [39].

As stated by Haklay [40], participation inequality does not only appear in online projects, but can also be observed in other types of projects such as environmental volunteering. Boakes et al. [41] studied patterns of contribution in three CS biodiversity projects, i.e., Greenspace Information for Greater London Community Interest Company (GiGL (www.gigl.org.uk)), iSpot (www.ispotnature.org) and iRecord (www.brc.ac.uk/irecord/), and they considered Greater London as their study area. In order to better understand the patterns of contribution of observers (biodiversity recorders), as well as to search for spatial and taxonomic biases in the observations, they analysed the dataset from the three aforementioned projects. They used a methodology to cluster volunteers based on three engagement metrics: Activity Ratio (number of days a volunteer was active divided by the total days they are linked to the project), Relative Activity Duration (number of days a volunteer was active divided by the overall study observation period in days), and Variation in Periodicity (average number of days elapsed between two sequential active days of an individual divided by the total average of days elapsed between active days of all individuals). As a result of this clustering, they identified three classes of volunteers: "dabbler", "steady", and "enthusiast". The dabbler category has the largest activity ratio, the lowest number of observations, the highest variation in periodicity and the least activity duration relative to the other two categories. Enthusiasts, on the other hand, are predominantly long-term observers and also the category that spends most time on the project and collection of observations. The category of enthusiasts consists of the smallest number of participants. Finally, the steady group has a profile type between the two categories of dabbler and enthusiast. The authors noted that dabblers were the clusters with the largest number of participants in all of the three projects evaluated, and that the number of participants gradually decreased from steady to enthusiast, a similar behaviour to that described in the Reader-to-Leader framework (see Figure 1). Moreover, similar to studies of online social communities and OpenStreetMap, the authors found that a few volunteers contribute with many 
observations and many volunteers contribute with a small number of observations. They stated that in the GiGL project, despite of having 1 million recorders, only four participants contributed over 10 percent of the records, while about 35 percent of participants contributed with only one record.

\section{Citizen Science Typology}

As stated in the introduction, the motivation of CS participants differs according to the typology of the CS project. We can therefore ask the question, "How are CS projects classified?". Several classifications for CS projects are defined according to the types of volunteer contribution to science $[1,14,42]$. In this article, we looked at Haklay's classification [14], in which he categorises CS projects into three types: classic citizen science, environmental management, and citizen cyber-science (CCS).

The first type, classic citizen science, mainly refers to the collection of observations from a broad and dispersed community of observers. Most of the cases in this category concentrate on the collection of environmental data such as biodiversity, water quality or meteorological observations, while also including other fields such as archaeology [14]. The evolution of mobile technology has made communication and observation collection easier in classic CS. Moreover, almost all of the collected observations in classic CS are geolocated, thanks to the integrated GPS chips in mobile devices, and therefore, are part of VGI projects [43].

The second type, environmental management, can be defined as citizens' engagement in defining environmental policies based on scientific information about the environment, as well as in creating participatory environmental decision making. Despite increasing attention to the field of CS, this type of CS is not yet widely researched, and there is inadequate evidence as to whether or not it will lead to the creation of environmental policies and regulations [44].

The third category, citizen cyber-science (also known as Virtual Citizen Science [28,45,46]), is defined by Francois Grey [47] as the use of web-based computer interactions to allow volunteers to contribute in scientific research through collaboration with scientists. Zooniverse (Zooniverse webpage: https://www.zooniverse.org/) is a CS web portal with hundreds of citizen cyber-science projects [46]. Haklay [14] proposed a categorization of citizen cyber-science with three subcategories: volunteered computing (VC), volunteered thinking (VT), and participatory sensing.

In VC projects, volunteers devote their computing resources to provide processing power to support computer-intensive tasks in a scientific project [47]. However, in VT projects, volunteers are using their cognitive ability to perform tasks [47], such as identifying objects in an image [8,48]. Some VT projects are part of VGI when the tasks involve geodata analysis, for instance georeferencing historical images in the sMapShot project [49]. Lastly, participatory sensing is the latest form of citizen cyber-science projects that uses mobile phone capabilities such as cameras, GPS receivers, different transceivers (mobile network, Wi-Fi, Bluetooth), and microphones to sense the environment; emotional maps [50], air-quality monitoring [51], water quality monitoring [52], and noise level monitoring [53] are examples of this category.

Curtis [30] proposed "citizen science games" [54] as the third category of citizen cyber-science. She suggested that it is a more appropriate category than Haklay's notion of "participatory sensing". Participatory sensing mainly regards data collection rather than data analysis, and therefore, it fits better in classic CS typology. Figure 4 shows the CS typology discussed above, which shows the categorisation defined by Haklay, except for participatory sensing, the third citizen cyber-science category, which is replaced by citizen science games (as suggested by Curtis). 


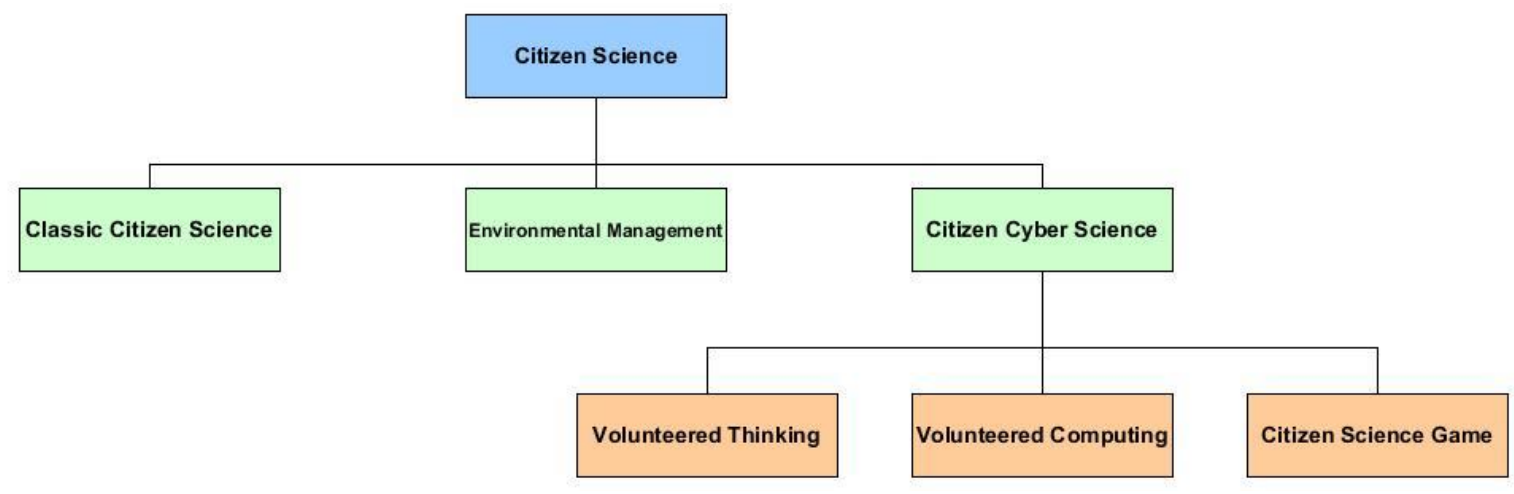

Figure 4. Citizen science typology as defined by Haklay [14], with the difference that for citizen cyber science, participatory sensing is replaced by citizen science game, as suggested by Curtis [30].

\section{Motivational Factors}

To better understand why people contribute to CS projects, it is essential to understand why people take part in voluntarily activities in the first place. Clary et al. [55] provides six potential functions (Volunteer Functions Inventory; VFI) that explain why people are motivated to do voluntarily activities. The suggested functions are as follows:

1) Values: volunteering provides the opportunity for individuals to express values towards altruistic and humanitarian concerns for others.

2) Understanding: volunteering provides individuals the opportunity for learning and gaining new skills and knowledge

3) Social: volunteering provides the opportunity for interactions with others, or engaging in an activity, which is viewed positively by others.

4) Career: individuals might obtain career-related benefits from volunteering activities (e.g. open source software developers, or contributors to Stack Overflow (https://stackoverflow. $\mathrm{com} /))$

5) Protective: volunteering may reduce guilt over being more fortunate than others. In a study of Red Cross volunteers [56], some of the volunteers indicated that they volunteer to avoid negative inner feelings.

6) Enhancement: volunteering provides the opportunity for some people to obtain satisfaction related to ego enhancement and self-esteem.

Batson et al. [57] studied "community involvement" and concluded that motivation can be categorised into four types based on the ultimate goal: egoism, altruism, collectivism, and principlism. Egoism refers to the increase of one's own welfare, altruism refers to the increase of other people's welfare, collectivism refers to the improvement of the welfare of a group, and finally, principlism is the maintenance of one or more moral principles, such as justice. They noted that each of these types of motivation has its own strengths and weaknesses; thus, approaches should be identified in order to increase community involvement, in such a way that the strength of one type of motivation will outweigh the weakness of another [57].

In addition to motivational studies in general volunteering, Ryan and Deci [58] studied motivation in the area of formal education. Depending on the reasons and objectives which give rise to an action, they distinguished two types of motivation: intrinsic and extrinsic [58]. Intrinsic motivation refers to performing an activity because it is satisfying or enjoyable. Extrinsic motivation, however, refers to doing something because of its outcome, such as receiving monetary rewards, feeling forced, or facing punishment. Some studies have discussed that while intrinsic motivation promotes creativity, extrinsic motivation prevents it [59]. It has been stated in other papers that a balance between intrinsic and extrinsic motivation, especially in gamified contributory platforms, can involve more participants and 
maintain their participation [60,61]. From a survey conducted by Lakhani and Wolf [62] on participants in Free/Open Source Software (F/OSS) development, they concluded that the most common form of motivation among participants was enjoyment-based intrinsic motivation, such as how one feels creative from being part of a project. In addition, a survey on the contributors of open-source projects showed that both internal (e.g., altruism) and external motivation (e.g., career-related motivation, direct compensation) played significant role in increasing participation [63].

These motivational studies are considered as the basis for understanding the motivation of volunteers in CS and VGI projects. Taking into account all of the above studies, Budhathoki [35] studied the motivation of OpenStreetMap participants and, as a result, set out a detailed list of possible forms of motivation for encouraging individuals to contribute to VGI projects. Below is the summarised list of intrinsic and extrinsic motivations defined by Budhatohoki [35]:

Intrinsic Motivations:

- Unique ethos

- Learning

- Personal enrichment

- Self-actualisation

- Self-image

- Fun

- Recreation

- Instrumentality

- Self-efficacy

- Meeting own needs

- Freedom of expression

- Altruism

Extrinsic Motivations:

- Career

- Strengthen social relations

- Project goal

- Community

- Identity

- Reputation

- Monetary return

- Reciprocity

- System trust

- Networking

- Social political

The types of motivation for individuals to contribute to OpenStreetMap vary, depending on how people are engaged in making contributions. There are a variety of ways that people engage to contribute to OpenStreetMap, such as by joining a local user group or a local chapter [64]. In addition, a very popular way of encouraging people to contribute is by arranging mapping parties or Mapathons [64,65]. Most Mapathons are organised for humanitarian reasons, such as mapping areas in developing countries where there are large gaps in OpenStreetMap data, or crisis Mapathons, where individuals are encouraged to start mapping shortly after a natural disaster occurs [66]. In addition, Kamptner and Kessler analysed the effect of a small-scale disaster (such as a building fire) on user contributions, and their study found a spike in OpenStreetMap data (ways, nodes and attributes) following incidents [67]. 
Although Mapathons have a major effect on the increase in OpenStreetMap contributions, a study by Hristova et al. indicated that these events are not enough to sustain participation, and that newcomers typically stop participating after the event is over, although experienced users continue to contribute [68]. Khanal et al. therefore analysed the Digital Internship and Leadership (DIL) strategy to address OpenStreetMap data disparities in rural Nepal by engaging and retaining the participation of youth mappers through virtual internships [69].

In addition, people also contribute to OpenStreetMap because they want to collect data for other applications (mostly in the form of games) that use OpenStreetMap. For example, an analysis of the impact of Pokémon GO (an augmented reality game) on OpenStreetMap contributions in South Korea showed a significant rise in the number of daily contributors and daily edits after the game was released, in order to enhance the in-game map [70]. They found that "park" and "water body" features were created or edited more by contributors who were motivated to contribute because of Pokémon GO than by other frequent OpenStreetMap contributors. They also stated that the increase in the number of edits/contributors fell to regular levels around 1.5 months after the release of the game.

Although it is difficult to derive all forms of motivation among OpenStreetMap participants given the broad possibilities of contributing to this project, Table 1 shows some of the key forms of motivation that we have taken from the literature for the above mentioned contribution possibilities.

Table 1. Some of the motivational factors to contribute to OpenStreetMap.

\begin{tabular}{|c|c|c|c|}
\hline \multirow{4}{*}{ Intrinsic } & Motivational factors ${ }^{\mathrm{i}}$ & $\begin{array}{c}\text { Detailed motivation to contribute } \\
\text { to OpenStreetMap }\end{array}$ & Example studies ${ }^{\mathrm{ii}}$ \\
\hline & Altruism & $\begin{array}{l}\text { Helping to map rural areas in } \\
\text { developing countries } \\
\text { Mapping to help after } \\
\text { natural disasters }\end{array}$ & {$[66,67,69]$} \\
\hline & Personal enrichment & $\begin{array}{l}\text { Learning digital leadership skills } \\
\text { Learning about } \\
\text { information technology } \\
\text { Understanding about geography } \\
\text { and mapping }\end{array}$ & {$[65,69,71]$} \\
\hline & Fun & $\begin{array}{l}\text { Enjoying the organised activities } \\
\text { in mapping parties } \\
\text { Improve the gameplay experience } \\
\text { in applications which use OSM }\end{array}$ & {$[70,72]$} \\
\hline \multirow[t]{3}{*}{ Extrinsic } & Strengthen social relations & $\begin{array}{c}\text { Being part of a } \\
\text { mapping community } \\
\text { Social networking and } \\
\text { making friends }\end{array}$ & {$[24,65]$} \\
\hline & Career & $\begin{array}{l}\text { Including learned (mapping) skills } \\
\text { in professional CV } \\
\text { Receiving mapping certificates for } \\
\text { future career }\end{array}$ & {$[24,65,69,71]$} \\
\hline & Monetary rewards & $\begin{array}{c}\text { Receiving school credits } \\
\text { Receiving an award (e.g., a mug or } \\
\text { a USB key) }\end{array}$ & {$[24,71]$} \\
\hline
\end{tabular}

\section{Reviewed Citizen Science Use Cases}

Throughout this section, we will review the motivational studies for different types of CS projects and extract the motivation types, taking into account the conceptual motivational studies listed in Section 4. To do so, we automatically downloaded 100 articles from Google Scholar with the keywords of "citizen science", "VGI", "motivation", "participation" and "engagement", from which we extracted 
the ones directly related to motivational studies in CS and VGI projects. A Python script was used to retrieve the articles automatically, providing the titles, authors, publication years and number of citations for each article. We found use cases for classic and online CS (VT, VC, and citizen science game) projects, but did not find studies analysing participant motivation in environmental management projects. The use cases were selected on the basis of three key criteria: the results of each use case are published in peer-reviewed journals, the number of citations, and the sample size of the participants whose motivation was analysed in each use case (minimum 100 respondents). All use cases conducted online surveys or interviews to determine the motivation type of their participants, along with other information, such as socio-demographic background. Various methods to identify motivation were used:

- Volunteers are presented with a list of possible types of motivation and are asked to rank them according to their priorities.

- Volunteers are presented with a list of possible types of motivation and are asked to give a score to each.

- Volunteers are asked open questions about their motivation, and hence, motivational factors are derived by coding free text responses. The approaches used to categorise the text responses are different and the theories used in such use cases are stated in this article.

Table 2 shows the CS typologies with their sample use cases.

Table 2. Use cases reviewed in this article for each citizen science typology.

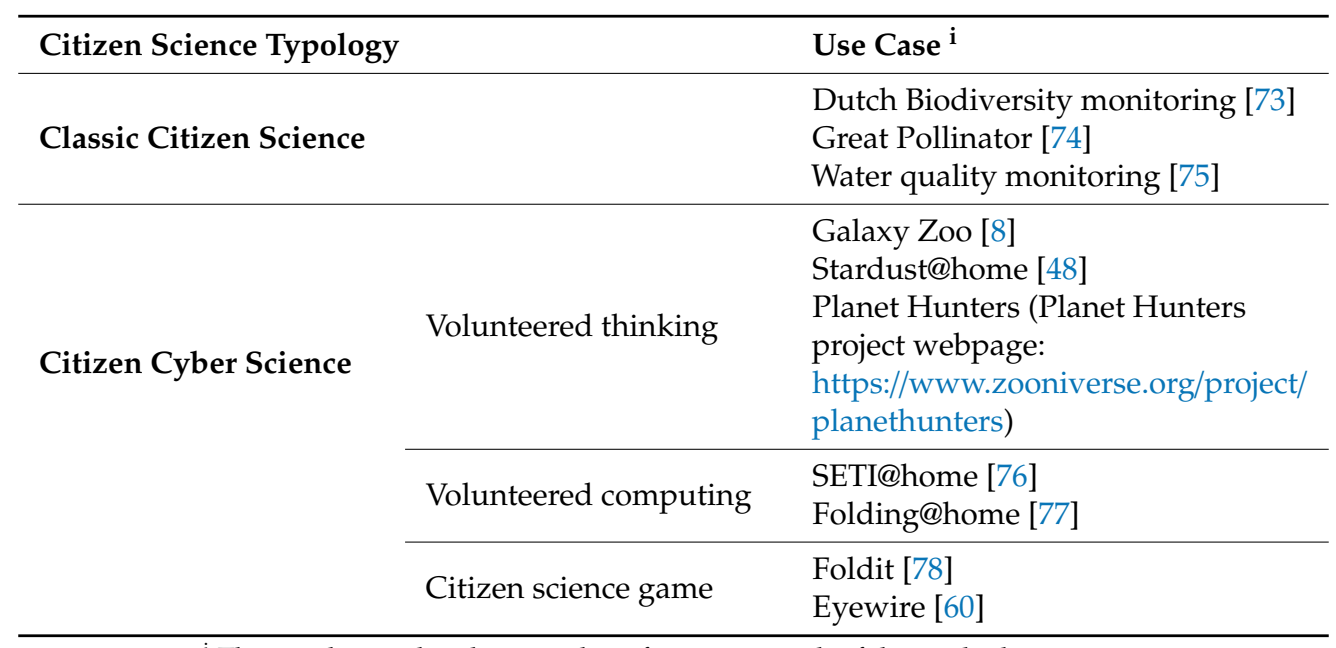

${ }^{\mathrm{i}}$ The numbers in brackets are the references to each of the studied use cases.

We studied three use cases for classic CS: Dutch biodiversity recorders [73], Great Pollinator Project (Great Pollinator Project: http://greatpollinatorproject.org/) [74], and water quality monitoring [75]. In the use case of Dutch national biodiversity recorders, an online survey was designed to address the following questions: What are the characteristics of citizen scientists with respect to their activities and socio-demographic backgrounds? What are their motivation to contribute to biodiversity monitoring? And what are their views on data ownership and data sharing? [73]. The most remarkable conclusion drawn from the authors' analysis of responses to the second question illustrated that the biodiversity recorders were mainly motivated by intrinsic motivation such as: learning about nature, spending time in the nature, and the desire to help by contributing to science and nature conservation [73]. In contrast, social motivation, such as interacting with others or building friendships and self-development, were given low importance [73].

Volunteers in the Great Pollinator project are encouraged to collect bee observations with the aim of understanding more about bees and other pollinators in New York City. Surveys were carried 
out to explore who the active volunteers are, their motivation for joining the project, the benefits they received by contributing to the project, and the difficulties they encountered when gathering and submitting data [74]. The results of the survey highlighted that the major motivation for most respondents was to learn about bees, accompanied by contributing to a scientific project and spending time in nature [74]. In contrast, social factors, such as being motivated by participating with family and friends, or participating in a team, were not strong forms of motivation for the participants, and just five percent of respondents listed them as their motivation.

Unlike the first two, the third classic CS use case is not about capturing biodiversity; rather, its objective is about monitoring water quality [75]. The top three forms of motivation among participants contributing to several water quality monitoring projects are helping the environment, helping a community, and being connected with nature [75]. Moreover, like other projects, building social networks and being known among a community are given little importance; however, working with like-minded people was an important motivation. They also compared motivation types among various age groups; some variations among younger and older participants were observed for social and career motivation. Even though career-based motivation and recognition among others were given low scores for all age groups combined, they were reported as stronger reasons to participate among younger participants.

For the first online CS typology, VT (Volunteered Thinking) projects, Galaxy Zoo [8], Stardust@home [48], and Planet Hunters were reviewed as the most well-known use cases in this category. Galaxy Zoo (the first and most well-known virtual CS project in Zooniverse) aims to encourage citizen scientists to classify the shape of galaxies in images [8]. As a result of open-ended interviews with Galaxy Zoo volunteers, 12 motivational factors were identified from the responses using the "grounded theory" [29]. The result of the interviews formed the basis for a second survey to analyse once more the motivation of Galaxy Zoo participants [29]. In the second survey, three approaches were used to determine the motivation type: first, rating the 12 motivational factors using a Likert scale; second, obtaining additional motivation as free text responses beyond these 12 predefined ones; and finally, asking respondents to indicate which motivation is the most important for them. The framework used in Galaxy Zoo to explain motivation is based on a theory called "expectancy-value", which states that an individual's motivation to perform an action depends both on the outcome they expect to occur (expectancy) and on the value they put on achieving that outcome [79]. The results illustrated that the main motivations were compassion for project objectives and interest in scientific content, while learning about science and participating in a social community appeared to be less motivating. Moreover, the interesting conclusion was that even though contribute was not the highest rated motivation in the Likert scale, it was selected as the primary motivation by a large group of respondents (nearly $40 \%$ ), regardless of their age, gender or level of education [29]. Furthermore, the authors mentioned that respondents who rated contribute as their primary motivation rated science higher, meaning that contributing to a scientific project seemed to be a strong motivator. Another interesting outcome was the negative relationship between the two motivation types, help and discovery, indicating that people whose motivation was to help science by classifying galaxies were less concerned about finding new and rare shapes in images of galaxies.

The next VT use case is Stardust@home, where volunteers (also known as "Dusters") classify images from the NASA Stardust spacecraft by searching for the tracks left by interstellar dust particles [48]. Prior to studying the motivation types among Stardust@home volunteers, a research model was defined, which included six motivation categories that may result in increasing participation: collective motivation (valuing the project goals), norm-oriented motivation (expectations of the reaction of other important people such as family, friends or colleagues), identification (being identified as a member of a group), intrinsic motivation, reputation, and social interactions [80]. The survey results illustrated that collective and intrinsic motivations were most widespread, while identification and norm-oriented motivations were of secondary importance. Similar to Galaxy Zoo, social interaction was not rated as a strong motivator. 
The third VT use case is Planet Hunter, which is also one of the Zooniverse projects; its goal is to analyse data obtained by the NASA Kepler Space Observatory. The Kepler Space Observatory monitors the stars and tracks their brightness every half hour. When a change of the brightness is detected, it could be attributed to a planet passing in front of it. Participants are required first to answer a question about the shape of the light curve and then to state whether or not there is a change in brightness. An online survey was performed to explain four major aspects related to Planet Hunter participants [30]: demographic characteristics, patterns of participation, motivation and reward, and interaction and contribution. Out of 160,000 registered volunteers at the time of the survey, only 118 individuals responded to it, and similar to other online CS projects, the majority of respondents were male. An open-ended question was asked to understand volunteers' motivation to participate in Planet Hunters, and the responses were coded to 13 different categories. Similar to other CS projects, interest in science and making a contribution to scientific research were the top two motivators. The possibility of making a new discovery was viewed as a strong motivation by approximately 22 percent of volunteers, and interestingly, similar to Galaxy Zoo, it was noted that it is important for volunteers to be recognised for their new discoveries by being included in the article acknowledgment or article co-authorship. The opportunity to learn was a motivator only for four per cent of respondents, although it should be noted that interest in learning about exoplanets comes into the category of interest in science. Moreover, giving importance to the project's goal and having fun were mentioned by a few people as their reasons for participating in Planet Hunters.

For the next online CS typology, VC (volunteered computing), we studied the survey results of the two use cases Folding@home (Folding@home: https://foldingathome.org/) and SETI@home [76]. Launched in 1999, SETI@home is the first and remains a successful VC project. It uses radio data to search for intelligent life in outer space. In order to study the motivation of SETI@home participants [81], the authors developed a framework which groups motivation into four main categories, considering whether they are intrinsic or extrinsic, and whether they are self-oriented or project-oriented. The four categories (Enjoyment, Value, Reputation and Enhancement) are as follows:

1) Enjoyment (intrinsic and self-oriented): enjoyment of interacting with others

2) Value (intrinsic and project-oriented): valuing the project' objectives

3) Reputation (extrinsic and self-oriented): gaining reputation among others in the project

4) Enhancement (extrinsic and project-oriented): seeing project's results get published in a scientific journal

In addition to the four categories listed above, two social factors related to the participation of volunteers in the project were addressed. The first, team affiliation, refers to volunteers who participate as a team, such as a university team or a national team; the authors hypothesised that team affiliation would result in increased contributions. The second social factor is the effect of project membership on participation. The authors hypothesised that lifetime membership in VC projects would be associated with a reduced level of contribution to the project.

The analysis of their survey data illustrated that the two self-oriented motivations, i.e., enjoyment and reputation, received higher scores compared to the project-oriented motivations, value and enhancement. The results showed that enjoyment and reputation were not related to the level of contribution, and this, as they concluded, might have been due to the nature of VC projects where contribution is passive, and enjoyment from social interactions in such projects is different from that in other kinds of online community-based projects. While enhancement was given a low score, the results showed a positive statistically significant relationship between enhancement and contribution level, which could be because seeing the results of the project published in scientific journals and acknowledging the majority of active participants is unconsciously causing people to make greater contributions. In addition, as hypothesised by the authors, affiliation in a team is positively linked with level of contribution; this is an interesting finding that demonstrates that even in VC projects where social interactions are not required for contribution, being part of a social group still plays an 
important role. Finally, there was a negative association between being a long-term member of the project ("the tenure of membership") and the level of contribution; the authors found this to be in line with contribution to other social communities, where contributors lose interest in projects when the excitement of community involvement fades over time. However, if the participants are affiliated with a team, the chances of losing interest are less compared to when they are contributing individually.

The next reviewed VC use case is the Folding@home project, which has the objective of understanding how protein molecules fold into their final 3D structure [77]. The project also aims to simulate this folding process millions of times more slowly than the natural process and to use this simulation to study the folding aspects in order to find cures for diseases such as cancer, Alzheimer's, and so on [77]. Therefore, volunteers' computing power is being used to help Folding@home scientists perform the intensive computational simulation tasks. Curtis [82] analysed participants of Folding@home to understand their demographic characteristics, to see why people contribute to the project, and finally, to see whether or not volunteers contribute in the same way. She found that the majority of participants were male (98 percent) with a large number either professionals or students in IT or related fields. She concluded that the key reason to contribute to Folding@home was to make a contribution to science or a worthy cause. Several participants were very interested in providing large-scale computing power, and sharing images of their advanced computer setups with other participants appeared to be a strong self-expression motivation to continue contributing to the project. The competition aspect and the desire to learn more about computer hardware were also strong motivators, especially among active participants. Similar to SETI@home, being part of a team was another important motivational factor.

Finally, for CS game, we reviewed the two well-known projects, Foldit (Foldit webpage: https: //fold.it/) and Eyewire (Eyewire webpage: https://eyewire.org/). Foldit is one of the first online CS games with an established online community of participants; its objective is to deduce protein structures [78]. Based on an online survey and semistructured interviews [61], 14 motivations to contribute to Foldit were identified, in which making a contribution to science, background interest in science, and intellectual challenge were the top three. Moreover, it was illustrated that the opportunity to collaborate with others and the communication features in Foldit, such as interaction between participants, were more motivating than the traditional game elements, such as pointing system, badges, and a leader board [61]. Of the large number of active participants, the desire to play computer games was an initial motivational factor for a minority. Nevertheless, the gamified features in Foldit are helpful in sustaining participation.

The second use case, Eyewire [60], is a web-based CS game asking people to identify connected areas in 3D transformed fMRI (Functional Magnetic Resonance Imaging) images in order to generate a detailed map of the human brain (see Figure 5). In order to understand motivation among Eyewire participants, a thematic coding approach was developed to identify motivational elements from the free text responses to the question of "Why do you play Eyewire?" [60]. A thematic coding was applied to the free text responses, and as a result, 18 motivation factors were extracted, which were then clustered into four categories: contributing to science; learning and personal interests; community and communication; and gaming and entertainment. The key reasons for participation appeared to be related to the value of the project, such as helping a beneficial cause, learning, and advancing scientific knowledge [60]. While gaming (the possibility to play a game) was not rated as a strong motivator, the effect of design features and game elements on participants' behaviour illustrated that these features, which facilitate communication among participants, resulted in increased contributions (similar to Foldit). Thus, the authors concluded that maintaining a balance between the game mechanics and the ultimate goal of learning about science and scientific tasks is the key to success in CS games. 
3D representation of an fMRI image

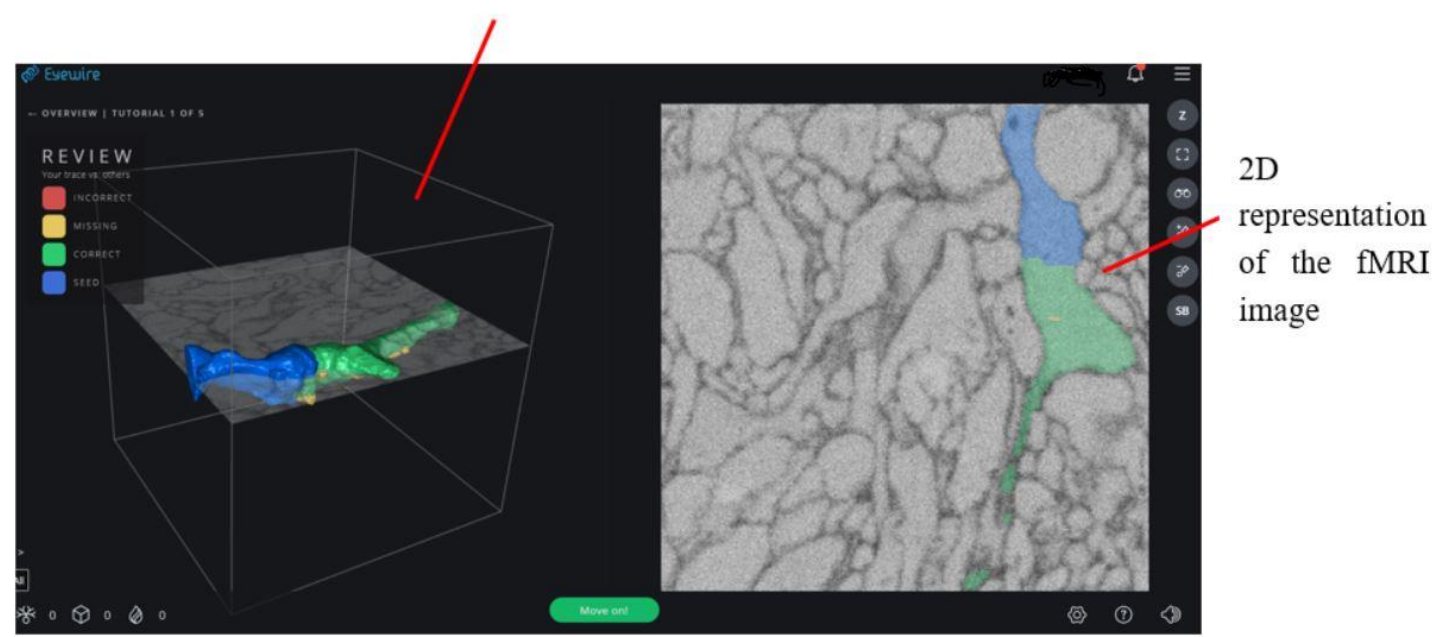

Figure 5. Eyewire interface (https://eyewire.org/explore).

\section{Motivational Framework}

In view of the study of motivation in voluntary activities and the analysis of various use cases of CS typologies, we identified a framework that categorises motivation by taking into account the types of CS projects. Since the number of use cases studying motivation on the basis of the level of participation are limited, and even those that have considered it are not complete and require further analysis, this framework does not classify motivation on the basis of the participation level, but rather, classifies it based on the strength of motivation types as rated by volunteers in each use case. Therefore, in addition to CS typology, motivation types are classified as primary (highly rated) and secondary (low-rated). This framework is a generalised version of Curtis's classification of the motivation types of Foldit participants [61]. Both frameworks classify motivation types on the basis of internal and external factors, and are therefore equivalent in their first two general levels. However, Curtis focused primarily on motivating factors in gamified CS projects [61], while our framework included all the other possible typologies (classic CS, gamified CS, volunteered thinking, and volunteered computing). In addition, Curtis defined the framework based on the survey responses of Foldit participants, whereas we considered at least two use cases for each CS typology. In our research, we considered the importance given to each motivation type by participants and categorised the results accordingly; this was not done in Curtis' research. Therefore, we conclude that our framework is a more complete version because of the addition of more use cases. Moreover, since we included more information on the strength of the motivation types, we suggest that our framework can help CS practitioners to obtain the information needed to recruit volunteers or to sustain participation in their projects. Table 3 presents the framework, which includes three main levels: 
Table 3. A framework to classify volunteers' motivation in citizen science projects.

\begin{tabular}{|c|c|c|c|c|c|c|c|c|c|}
\hline \multirow{4}{*}{ Level 1} & \multirow{4}{*}{ Level 2} & \multicolumn{8}{|c|}{ Level 3} \\
\hline & & \multirow{2}{*}{\multicolumn{2}{|c|}{ Classic Citizen Science }} & \multicolumn{6}{|c|}{ Citizen Cyber-Science } \\
\hline & & & & \multicolumn{2}{|c|}{ Citizen Science Game } & \multicolumn{2}{|c|}{ Volunteered Thinking } & \multicolumn{2}{|c|}{ Volunteered Computing } \\
\hline & & Primary & Secondary & Primary & Secondary & Primary & Secondary & Primary & Secondary \\
\hline \multirow[t]{3}{*}{ Intrinsic } & Altruism & $\begin{array}{l}\text { contribution to science } \\
\text { nature conservation } \\
\text { helping science } \\
\text { and environment }\end{array}$ & & $\begin{array}{l}\text { Contribution to science } \\
\text { desire to support a } \\
\text { worthy cause (such as } \\
\text { finding a cure for } \\
\text { a disease) }\end{array}$ & & $\begin{array}{l}\text { Contributing to science } \\
\text { Helping the scientists }\end{array}$ & $\begin{array}{l}\text { giving importance to } \\
\text { goals of the project }\end{array}$ & $\begin{array}{l}\text { desire to help scientific } \\
\text { projects and } \\
\text { contribution to } \\
\text { something worthy } \\
\text { offering personal } \\
\text { computing power for } \\
\text { scientific analysis }\end{array}$ & $\begin{array}{l}\text { to share acquired } \\
\text { knowledge over years } \\
\text { with others }\end{array}$ \\
\hline & Fulfilment & $\begin{array}{l}\text { Interest in learning } \\
\text { about nature } \\
\text { and environment }\end{array}$ & $\begin{array}{l}\text { understanding the } \\
\text { scientific process }\end{array}$ & $\begin{array}{l}\text { Interest in science } \\
\text { learning new } \\
\text { knowledge and } \\
\text { mastering a new topic }\end{array}$ & & $\begin{array}{l}\text { Interest in science and } \\
\text { desire to be connected to } \\
\text { science } \\
\text { learning about } \\
\text { science(for instance } \\
\text { learning about galaxies) }\end{array}$ & & $\begin{array}{l}\text { enthusiast in fully } \\
\text { utilizing the } \\
\text { computing power }\end{array}$ & $\begin{array}{l}\text { learn and acquire } \\
\text { new skills }\end{array}$ \\
\hline & Enjoyment & $\begin{array}{l}\text { Spending time in } \\
\text { the nature } \\
\text { Outdoor recreation }\end{array}$ & & $\begin{array}{l}\text { satisfaction of solving } \\
\text { complicated problems } \\
\text { Intellectual challenge }\end{array}$ & playing computer games & making new discoveries & $\begin{array}{l}\text { having fun by doing } \\
\text { the activities such as } \\
\text { classifying or } \\
\text { identifying objects } \\
\text { in images }\end{array}$ & $\begin{array}{l}\text { satisfying feeling of } \\
\text { being useful }\end{array}$ & \\
\hline \multirow[t]{3}{*}{ Extrinsic } & Community & $\begin{array}{l}\text { working with } \\
\text { like-minded people }\end{array}$ & $\begin{array}{l}\text { Interaction with others } \\
\text { meeting new people } \\
\text { group data collection }\end{array}$ & $\begin{array}{c}\text { interaction with } \\
\text { other participants } \\
\text { being part of a diverse } \\
\text { community with } \\
\text { shared goal }\end{array}$ & & & $\begin{array}{l}\text { being identified as a } \\
\text { member of a group } \\
\text { social interaction } \\
\text { with others }\end{array}$ & $\begin{array}{l}\text { being affiliated to } \\
\text { a team }\end{array}$ & $\begin{array}{l}\text { interaction with } \\
\text { others and } \\
\text { build relationship }\end{array}$ \\
\hline & Ego enhancement & & $\begin{array}{l}\text { gain recognition among } \\
\text { other participants }\end{array}$ & $\begin{array}{l}\text { compete with } \\
\text { other players } \\
\text { gain recognition as top } \\
\text { players in leader board }\end{array}$ & $\begin{array}{l}\text { improve self-status } \\
\text { among other players }\end{array}$ & $\begin{array}{l}\text { to be offered } \\
\text { co-authorship in } \\
\text { scientific articles } \\
\text { to be acknowledged in } \\
\text { scientific articles } \\
\text { being named after } \\
\text { a discovery }\end{array}$ & $\begin{array}{l}\text { being among firsts to } \\
\text { make scientific } \\
\text { discoveries }\end{array}$ & $\begin{array}{l}\text { seeing the results of the } \\
\text { project published in a } \\
\text { journal paper } \\
\text { being acknowledged as } \\
\text { active participant in } \\
\text { an article }\end{array}$ & $\begin{array}{c}\text { competition } \\
\text { self-expression } \\
\text { towards having } \\
\text { a higher } \\
\text { computing power }\end{array}$ \\
\hline & Future return & & career-based benefits & $\begin{array}{l}\text { gain knowledge from } \\
\text { the games for personal } \\
\text { reasons such as school } \\
\text { grade or career }\end{array}$ & $\begin{array}{l}\text { receiving badges } \\
\text { and points } \\
\text { Monetary rewards }\end{array}$ & & $\begin{array}{l}\text { receiving extra } \\
\text { awards such as t-shirt, } \\
\text { certificates, or } \\
\text { virtual badges }\end{array}$ & $\begin{array}{l}\text { obtain credits for } \\
\text { a course }\end{array}$ & \\
\hline
\end{tabular}


Level 1: The most general level, that classifies motivation types into two categories: intrinsic or extrinsic. As mentioned earlier, intrinsic motivations are when people perform an action because of the inner positive feeling they get; in comparison, extrinsic motivations are those when people perform an action because of what they receive in return, such as monetary rewards or reputation.

Level 2: At this level, intrinsic and extrinsic motivations are broken down into subcategories. Taking into account the motivation to contribute in VGI projects described by Budhathoki [35], as well as motivation in various CS use cases, we identified the key motivational factors in CS projects. In addition to CS and VGI projects, to identify the categories in this level (in order to have a comprehensive overview of motivational factors), we considered the motivation to contribute to other forms of voluntary activities, such as free and open source software development [62]. These categories were defined in such a way that all the motivators found in the CS use cases were allocated to a category, and no motivation type remained unclassified. Although all motivation types were classified, certain among them could be allocated to two categories; for example, in a citizen science game, earning a badge could be classified as reputation and a tangible reward. In addition, certain motivators were integrated into just one category, for example, the future return category included the expectation of monetary rewards, or the expectation that valuable information would be obtained, e.g., to find/promote a career, or even the expectation that school grades would be improved as a result of participation. Therefore, given the review of previous motivational studies and the CS use cases with different objectives and designs, we believe that new additional motivators from other use cases will fit into the defined categories at this level. However, this framework can be further expanded, given that new motivation types are identified that could not be assigned to any of the specified categories. Accordingly, we ended up with six categories of motivation types at level 2, three intrinsic and three extrinsic. The categories at level 2 are as follows:

The intrinsic motivation are subcategorised as "altruism", "fulfilment", and "enjoyment":

- Altruism: Volunteers are motivated to contribute to CS projects to help scientists advance their research or contribute to a worthy cause.

- Fulfilment: Volunteers participate in CS projects (in order) to fulfil an interest in science or the desire to gain new knowledge.

- Enjoyment: Volunteers contribute to CS projects because they want to enjoy doing an activity other than their profession, such as having fun while playing a computer game or spending time in nature (e.g., bird watchers).

The extrinsic motivation types are subcategorised as "community", "ego enhancement", and "expected future returns":

- Community: Volunteers contribute to CS projects because of the social aspects of volunteering, such as meeting new people or being part of a team with a shared goal.

- Ego enhancement: Volunteers contribute because they want to improve their self-esteem or to have a good reputation among others. Examples include being mentioned in the website of a project as the most active participant, or being acknowledged in a paper.

- Expected future returns: Volunteers participate because they expect to achieve something in exchange for their contribution, such as monetary rewards, certificates, school grades, or to win points and badges in a gamified project.

Level 3: In this level, the motivation types were broken down according to details which were specific to each project. The categorisation of the first and second levels was more general and independent of project type; however, in this level, the motivation types were classified, taking into account the CS typology (check Table 3). In addition, a general pattern was identified in such a way that motivation types which had been given top priority in one use case were given high importance in other use cases of the same typology. The same pattern was observed for low-ranked motivation types. Taking into account this pattern and the importance given to motivation in each typology, motivation 
types were further categorised into two other subcategories: primary and secondary motivation. Primary motivation types, as defined in this framework, were of considerable importance to the majority of volunteers in the CS project. For example, in all classic CS use cases, high scores were given to the motivation helping the environment by a majority of respondents, or in VC projects, recognition among others (ego enhancement) was a strong motivator to contribute among a broad number of respondents, even if passively reported (e.g., the effect of acknowledging participants on increasing their level of contribution). In addition, in most cases, the primary motivating factors were essential to sustain the participation of enthusiasts and serious contributors. On the other hand, secondary motivators were those given lower ranks by volunteers, and were selected as the central motivating factors by a smaller number of participants, relative to primary motivations. For instance, in gamified CS projects, the desire to play a computer game was the main motivation for a relatively small group of participants, or in VT projects, receiving monetary rewards was mentioned as a central motivation by few respondents in all the studied VT use cases. Secondary motivators are mostly important to encourage casual volunteers to contribute, or to encourage potential volunteers to initiate participation. This categorisation does not imply dismissing people driven by secondary motivators, but it is a means of recognising the different levels of motivation when designing a project to achieve a balance between increasing the level of participation of committed volunteers, motivating casual volunteers to remain interested in the project, and recruiting new participants.

The classification in Table 3 indicates that the motivation types among participants in one type of CS project are similar, and different than those of another CS category. Although motivating factors varied based on the project type, certain motivational factors were common in all types of CS projects. For instance, contribution to a scientific project and interest in science were reported as strong motivators in almost all use cases. Looking more into specific types, we found that in classic CS projects, intrinsic motivators play a more important role in engaging participants than extrinsic ones. Nonetheless, both intrinsic and extrinsic motivators are important in engaging people in virtual CS projects. For instance, ego enhancement, such as being offered a paper co-authorship, was reported as a strong motivational factor in VT projects. Moreover, contrary to what seems to be the case in CS games, traditional game elements such as pointing systems, leader boards, and badges are not the primary reasons for recruiting volunteers; in other words, volunteers do not participate in CS games because of their enthusiasm for playing games, but because they are interested in contributing to science [26]. Nevertheless, game elements are helpful in maintaining participation by, for example, creating a sense of competitiveness amongst the players or feeling like they are part of a community when playing as a team [26]. Some of the participants in VT and VC projects, however, were strongly motivated by future returns and not necessarily by monetary rewards, but by achieving better school grades or earning certificates, for instance. Although participants from the same CS type tended to have similar motivations, the strength of motivation types among participants of one use case may be different from another use case. For instance, in VT projects, the motivation of valuing the project goals was mentioned in all VT use cases, but it was rated as a stronger motivator in Stardust@home than in Planet Hunters.

A comparison of the motivational framework in Table 3 with that of the OpenStreetMap in Table 1 reveals that both in CS and OpenStreetMap, learning and altruism are the two primary motivators among participants. However, altruism in OpenStreetMap primarily refers to humanitarian mapping purposes (e.g., mapping affected areas after natural hazards), while in CS, it is mostly focused on preserving nature or contributing to science, or helping scientists to accomplish the objectives of their projects. In CS projects, social interactions provide greater motivation for participating in online CS projects compared to classic CS, while in OpenStreetMap, social interaction is an important motivator for joining Mapathons and contributing to OpenStreetMap. As mentioned earlier, depending on the broad variety of ways of contributing to OpenStreetMap, the motivation types differ greatly, and an in-depth comparison of motivation types in OpenStreetMap and CS is a subject for further study. 


\section{A Discussion of the Framework with a Classic Citizen Science Use Case}

This section presents a discussion of the framework of a classic CS project in addition to what was previously studied. Therefore, we first present our biodiversity Classic CS project, called BioPocket, and then present the results of an online survey, which was conducted to understand the motivation types among potential BioPocket participants and their socio-demographic variables. The survey was designed in Google Forms, and the R (www.r-project.org) and Python (www.python.org) programming languages were used to analyse the responses.

BioPocket is a CS biodiversity project (a mobile application) with the objective of encouraging citizens to learn about biodiversity and take actions in favour of it [83]. A variety of activities that can be performed to promote biodiversity are specified in this project; these actions are categorised according to a number of criteria, such as theme, difficulty, importance, etc. Actions may range from simple ones, such as taking pictures of species, to more complicated ones, such as building a birdhouse or constructing a pond in a garden. Participants can learn how to undertake an activity by following the instructions given in the application. Details are given, such as what supplies are needed for each particular action, or how long each action takes. In addition, participants may monitor what action is being taken in their neighbourhood, using the interactive map in the application (Figure 6).

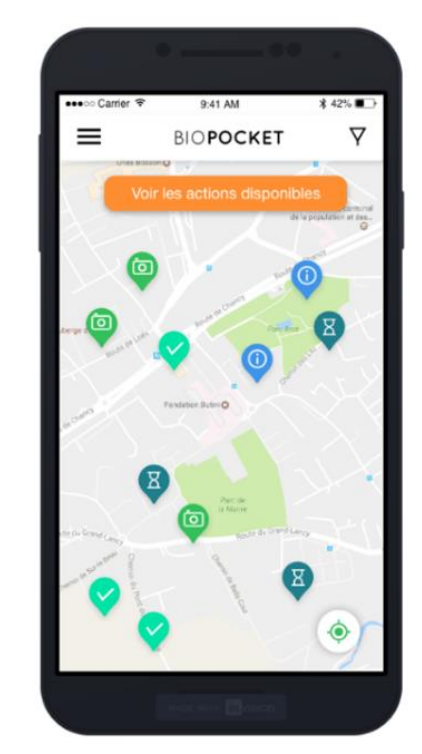

Figure 6. The interactive map in BioPocket application. Participants can check the type and location of actions, as well as the biodiversity points of interests around them.

We conducted an online survey to understand the characteristics of potential participants and their motivation to participate in BioPocket. In this survey, we gathered information in four categories: socio-demographic information, backgrounds of participants on environmental activities, reasons to contribute to BioPocket, and their views on the usage of mobile apps (in terms of security aspects and experience with the use of mobile applications). In the section on socio-demographic information, we obtained data on the age, level of education and occupation of the respondents. In addition, in order to conduct a spatial analysis, we collected the postal codes of the respondents and the type of housing in which they live (e.g., apartment, villa, etc.). In analysing the responses, it was our objective to understand:

- The correlation between motivation types

- The correlation between motivation types and other variables (age, education, residence type, etc.)

The survey was distributed via email and a Facebook campaign, resulting in 94 responses. The majority of respondents were between $15-24$ and $25-34$ years of age, i.e., $41 \%$ and $38 \%$ respectively, 
and the number of male respondents was almost 14 per cent higher than that of female respondents. The majority of respondents were from the French-speaking cantons of Switzerland (Figure 7), with the cantons of Vaud and Geneva comprising $60.9 \%$ and $17 \%$, respectively (as set out in the Facebook campaign for the distribution of ads to citizens from French-speaking cantons).

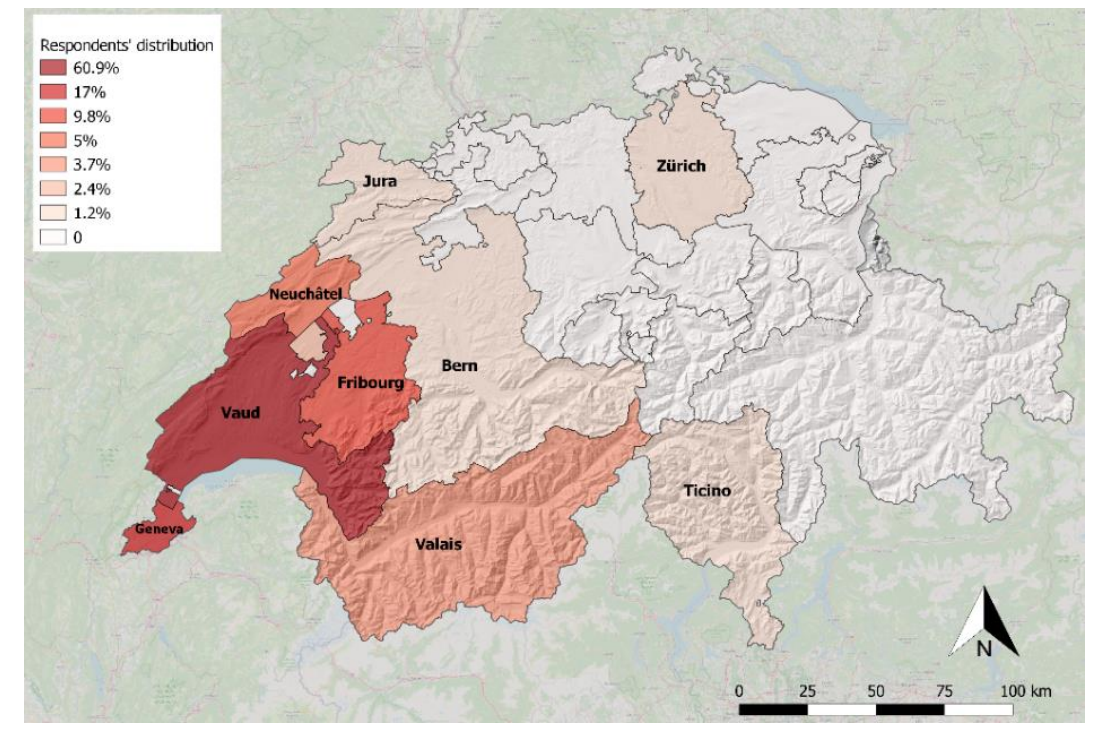

Figure 7. Distribution of BioPocket survey respondents within Switzerland. The regions with no responses are not labelled on the map.

In addition to demographic information, a ranking was obtained on the basis of the average score given to each motivation type. The scores ranged from 1 to 8 ; Figure 8 presents the ranking of the motivating factors. Similar to the motivation types of classic CS in Table 3, in this survey, the participants also gave a higher score to intrinsic, nature-related motivators, as the top three motivating factors were helping nature, spending time in nature, and learning about biodiversity. On the other hand, extrinsic motivation types, such as social interactions, gaining recognition among others (ego enhancement) and expecting future returns, such as awards or certificates, were given less priority and were ranked lowest. These findings are in accordance with the results from the use cases related to the classic CS typology in the framework.

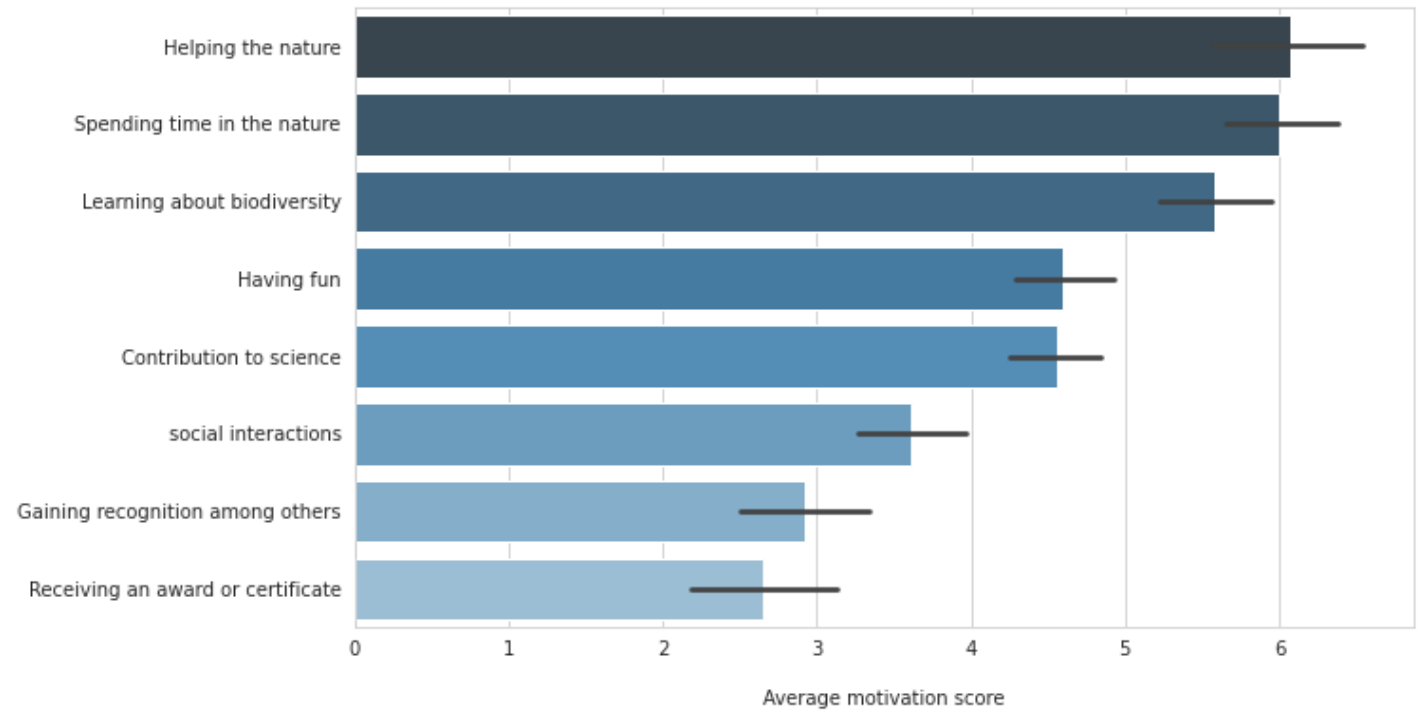

Figure 8. Motivation ranking to participate to BioPocket project [83]. Motivating factors were given scores from 1 to 8 , and the ranking was based on the average score give to each. 
Correlations between motivation types were obtained using the Pearson correlation coefficient [84] shown in Figure 9. There was a positive statistically significant correlation $(p$-values $<0.001)$ between of helping nature, learning about biodiversity and spending time in nature, as well as between the three extrinsic motivators, i.e., social interactions, gaining recognition among others, and receiving awards or certificates. On the other hand, these intrinsic and extrinsic motivation types were significantly negatively correlated, meaning that respondents who gave higher scores to intrinsic nature-related motivators gave lower scores to extrinsic motivators. This corresponds to what was observed in the classic CS use cases in the framework.

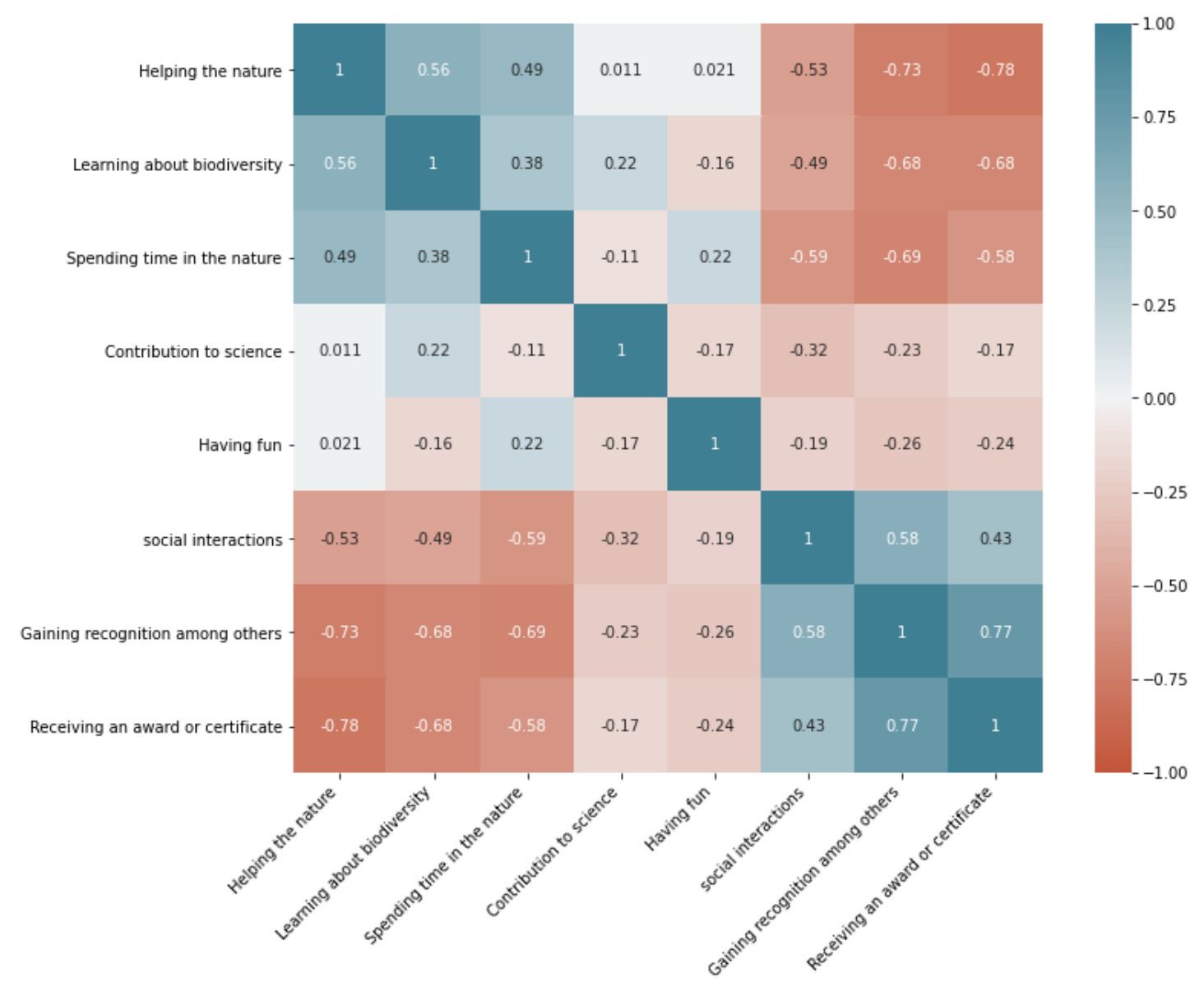

Figure 9. Correlation between motivation types based on the scores given by respondents. All the correlations are statistically significant with $p$-values $<0.001$.

Correlations between the motivation type and other socio-demographic variables (e.g., age and education) were obtained using the Polyserial correlation coefficient [85]; the results illustrated weak correlations. On the other hand, to evaluate the correlation between numerical and nominal variables, we used a statistical measure called the Freeman Theta coefficient [86], which ranges from 0 to 1 , where 0 implies no association between variables and 1 indicates a perfect association. The results of this test on motivation and residence type illustrated that there was a moderate association between residence type and the two motivations of spending time in the nature and gaining recognition among others, with theta coefficients of 0.32 and 0.34 , respectively. To further illustrate the results, we generated boxplots for the residence type versus the two aforementioned motivating factors (in Figure 10, residence types are aggregated into two types: apartment and villa). From the box plots, it can be seen that people living in apartments (mainly located in densely urbanised areas) placed more value (about 1 score on average) in spending time in nature relative to people living in villas (mainly located in open urban areas surrounded by more green areas compared to central urban areas). 
In contrast, gaining recognition among others was given higher scores by people living in villas than those living in apartments. Although these results require further investigation, a tentative conclusion would be that people living in densely urbanised zones are motivated to contribute to biodiversity CS projects because they want to escape city life and to spend more time in nature, while people living in less urban areas appear to be motivated not only by intrinsic factors related to biodiversity, but also by social interactions and being recognised among others. Therefore, the area where people live can have an important influence on volunteer participation. CS practitioners should consider this factor while recruiting and sustaining participation (e.g., designing an interactive app to teach volunteers about biodiversity, acknowledging volunteers, and organising social events to perform group data collection).
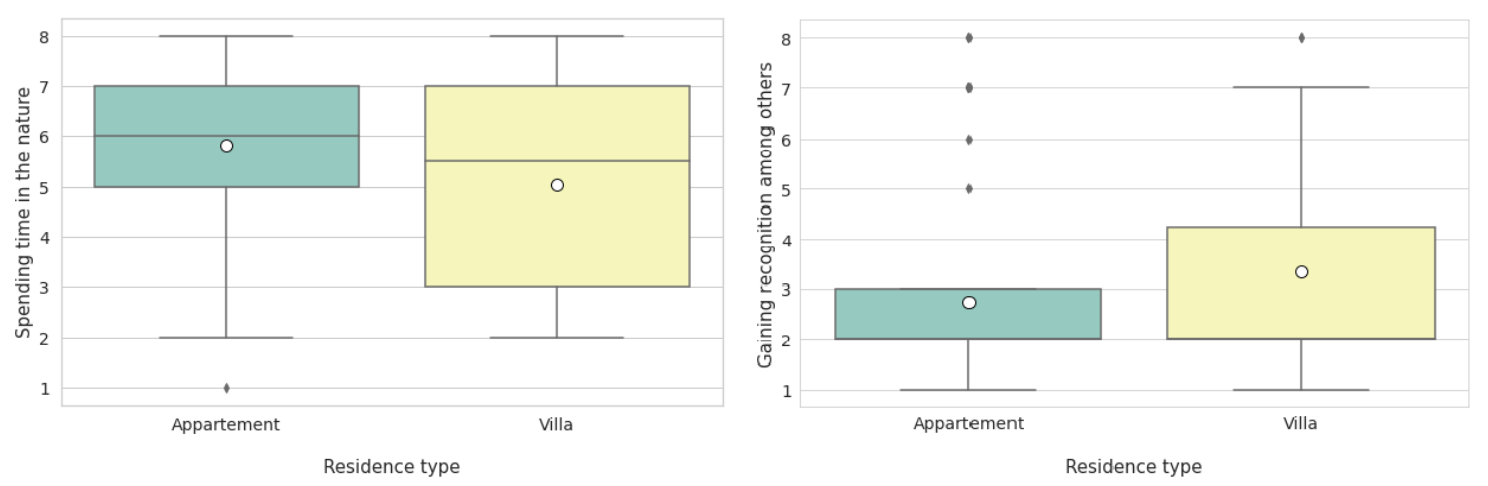

Figure 10. Boxplots of respondent's residence types versus motivation of spending time in the nature (on the left), and gaining recognition among others (on the right). The residence types are aggregated to two types, i.e., Apartment and Villa.

\section{Conclusions and Future Perspectives}

Public participation in scientific research is taking scientific projects to the next level, and open science is developing a deep engagement between members of the public and scientists. The number of CS projects has increased significantly in recent years, and the number of peer-reviewed publications in environmental CS has increased almost fivefold from 2010 to 2015 [87]. Considering this growth in the CS field, it is essential to understand the reasons why people contribute to such projects in order to recruit more volunteers and to sustain their participation [2]. Although CS projects are focused on different topics, they can be grouped into certain categories, taking into account the project tasks and objectives; the reasons why people contribute to CS projects differ, depending on the project type. The majority of studies on participant motivation in CS projects are specific to one use case, and thus, a generalised framework summarising the outcomes of these articles is missing. Therefore, in this article, we defined a framework in which the motivation types leading people to contribute to CS projects are summarised and classified based on the typology of CS and the strength of the motivator for each typology.

In this paper, we first discussed the various categories of CS projects and then studied motivational factors based on the different categories of CS. A literature review was conducted on the motivation in Classic CS, and in online CS projects (volunteered thinking, volunteered computing, and citizen science game). We noticed that participants in projects with the same typology seem to have similar motivations. We therefore conclude that motivating factors are very much related to the types of tasks to be performed by volunteers. In the defined motivational framework, the motivation types were classified into intrinsic and extrinsic ones, and were then further broken down into more detailed categories. Some of these motivations were self-oriented, such as interest in learning, or desire to be part of a community, while others were oriented towards the project and its objectives, such as trying to help scientists advance in their research, or valuing the goals of the project. Several patterns were observed while studying the motivation for CS projects. One of the main findings was that 
contribution to science and research projects, regardless of the type of CS, was a strong motivation for the majority of participants of all use cases. Another interesting factor was the impact of social interactions for motivating and sustaining participation. In some projects, such as CS games, interaction between participants or between participants and scientists appeared to be a strong motivation for volunteers to keep contributing to the project. In VC and VT projects, even though social interactions and building relationships were not reported as strong motivating factors among participants, being involved in a community and being affiliated with a team resulted in increased contribution and sustained participation. In classic CS projects, where the goal is primarily to collect observations (mostly environmental observations, e.g., biodiversity, water quality, air pollution, etc.), intrinsic factors, e.g., nature conservation or the interest in learning about science and the environment, have been widely documented as strong motivators. Furthermore, though collaborating with like-minded people is valued in classic CS projects, social interactions or seeking to create social connections are not strong motivators for participants.

The most important thing in all use cases is to maintain a balance between attaining the objectives of the project and engaging volunteers. It is essential that project designers create the project in ways that meet/suit the expectations of a wide number of participants. For instance, in CS game projects, if the only emphasis is on game elements and the opportunity to learn about science is absent, a substantial number of participants may stop participating soon after their initial participation. As another example, in VT and VC projects, it is important to share the findings and new publications of the projects with the volunteers in order to let them see that their participation is appreciated and recognised.

The motivational framework defined in this article can be useful for researchers working on VGI and CS projects to understand the potential factors which can motivate individuals to join and contribute to their specific project. Some suggestions for CS practitioners and project coordinators are offered below:

- Interest in learning something new: to include creative learning opportunities in the project using new technology such as augmented reality [88], or to add more information such as text and videos to a web page or project web/mobile application. In addition, project coordinators can provide the opportunity for volunteers to meet with experts by organising workshops and seminars (or activities such as mapping parties).

- Contribution to a scientific project: provide updates to participants on their contribution and let them know that their efforts have been taken into account, and communicate the results to them. Besides the general feedback on final results and publications, it is important to give detailed feedback to volunteers on their individual contributions, either through expert assistance or through automatic feedback generated using machine learning techniques, and to provide participants with informative information on the project topics [89].

- Interest in social interactions: provide an opportunity for volunteers to interact with others through social forums, chatting functionality in the project application, and organising events such as field activities for group data collection.

- Ego enhancement: inform volunteers that they will be acknowledged in publications and on social media. Moreover, some volunteers would like to receive written cards, while some prefer to gain recognition by receiving certificates. An additional possibility would be to acknowledge top ranked contributors in scientific seminars and conferences [24].

In addition to the aforementioned suggestions, it is essential to consider the socio-demographic background of volunteers before recruiting or sustaining their participation. Younger volunteers, for example, are more motivated by learning, career-based, and social interaction factors than older volunteers, while older volunteers are more motivated by contributing to scientific and research projects and having the feeling that they are spending their time in a productive way [75]. In addition, although this requires further research, project coordinators need to consider variations in motivating factors among new volunteers and others who have been in the project for longer time. For example, 
in a project of water quality monitoring [75], the authors mentioned that new participants were more motivated by their interest in learning than were the veteran volunteers. In order to better understand the needs of the volunteers, it is essential to communicate with them and to value their contributions, and as a result, to increase the level of participation [74].

Furthermore, as the framework includes an overview of motivational variables in CS projects, it may be used as a guide for studying motivation types in other CS use cases, for instance, to design motivational surveys or to decode the free text responses from surveys with open questions about participant motivation.

As with all other research, this framework has certain limitations that need to be discussed in the future. As described earlier, the CS typology in the framework is the one identified by Haklay, and the need to look at other typologies to make a comparison with the framework is an area for further study. Another factor is that we did not find any motivational studies on CS environmental management; thus, this typology is absent from the framework, though we are trying to continue the study, taking into account all types of contribution to CS projects. Another important element is that the correlation between motivation types and level of participation is discussed in only few use cases, and thus, including the level of participation in the framework remains a point for a potentially different aggregation of motivation types. Additional discussion of the framework used in use cases from other typologies besides classic CS will be another aspect in future work. Finally, the effect of feedback on motivating volunteers and maintaining participation is not adequately addressed in CS projects, and thus, remains an area for further investigation.

Funding: This research was partially funded by HES-SO, BioPocket project grant number 53886 .

Acknowledgments: The authors would like to gratefully acknowledge the BioPocket team especially the Media Engineering Institute of HEIG-VD for their interesting input during the meetings.

Conflicts of Interest: The authors declare no conflict of interest.

\section{References}

1. Bonney, R.; Ballard, H.; Jordan, R.; McCallie, E.; Phillips, T.; Shirk, J.; Wilderman, C. Public Participation in Scientific Research: Defining the Field and Assessing Its Potential for Informal Science Education; A CAISE Inquiry Group Report; Online Submission: Washington, DC, USA, 2009.

2. Land-Zandstra, A.M.; Devilee, J.L.A.; Snik, F.; Buurmeijer, F.; Broek, J.M.V.D. Citizen science on a smartphone: Participants' motivations and learning. Public Underst. Sci. 2015, 25, 45-60. [CrossRef] [PubMed]

3. Hecker, S.; Haklay, M.; Bowser, A.; Makuch, Z.; Vogel, J.; Bonn, A. Innovation in open science, society and policy-Setting the agenda for citizen science. Citzen Sci. 2018, 1-24. [CrossRef]

4. Conrad, C.T.; Hilchey, K.G. A review of citizen science and community-based environmental monitoring: Issues and opportunities. Environ. Monit. Assess. 2010, 176, 273-291. [CrossRef] [PubMed]

5. Delaney, D.G.; Sperling, C.D.; Adams, C.S.; Leung, B. Marine invasive species: Validation of citizen science and implications for national monitoring networks. Biol. Invasions 2007, 10, 117-128. [CrossRef]

6. Danielsen, F.; Burgess, N.D.; Jensen, P.M.; Pirhofer-Walzl, K. Environmental monitoring: The scale and speed of implementation varies according to the degree of peoples involvement. J. Appl. Ecol. 2010, 47, 1166-1168. [CrossRef]

7. Schade, S.; Tsinaraki, C. Survey Report: Data Management in Citizen Science Projects; Publication Office of the European Union: Luxembourg, 2016.

8. Lintott, C.J.; Schawinski, K.; Slosar, A.; Land, K.; Bamford, S.P.; Thomas, D.; Raddick, M.J.; Nichol, R.C.; Szalay, A.S.; Andreescu, D.; et al. Galaxy Zoo: Morphologies derived from visual inspection of galaxies from the Sloan Digital Sky Survey. Mon. Not. R. Astron. Soc. 2008, 389, 1179-1189. [CrossRef]

9. Khatib, F.; Cooper, S.; Tyka, M.D.; Xu, K.; Makedon, I.; Popović, Z.; Baker, D.; Players, F. Algorithm discovery by protein folding game players. Proc. Natl. Acad. Sci. USA 2011, 108, 18949-18953. [CrossRef]

10. Swan, M.; Hathaway, K.; Hogg, C.; McCauley, R.; Vollrath, A. Citizen science genomics as a model for crowdsourced preventive medicine research. J. Particip. Med. 2010, 2, e20. 
11. Cooper, C.B.; Dickinson, J.; Phillips, T.; Bonney, R. Citizen Science as a Tool for Conservation in Residential Ecosystems. Ecol. Soc. 2007, 12, 11. [CrossRef]

12. Cohn, J.P. Citizen Science: Can Volunteers Do Real Research? BioScience 2008, 58, 192-197. [CrossRef]

13. Goodchild, M.F. Citizens as sensors: The world of volunteered geography. GeoJournal 2007, 69, 211-221. [CrossRef]

14. Haklay, M. Citizen Science and Volunteered Geographic Information: Overview and typology of participation. In Crowdsourcing Geographic Knowledge; Springer: Dordrecht, The Netherlands, 2013; pp. 105-122. [CrossRef]

15. Crowston, K.; Prestopnik, N.R. Motivation and Data Quality in a Citizen Science Game: A Design Science Evaluation. In Proceedings of the 2013 46th Hawaii International Conference on System Sciences, Wailea, HI, USA, 7-10 January 2013; pp. 450-459.

16. Crall, A.W.; Newman, G.J.; Stohlgren, T.J.; Holfelder, K.A.; Graham, J.H.; Waller, D.M. Assessing citizen science data quality: An invasive species case study. Conserv. Lett. 2011, 4, 433-442. [CrossRef]

17. Alabri, A.; Hunter, J. Enhancing the Quality and Trust of Citizen Science Data. In Proceedings of the 2010 IEEE Sixth International Conference on e-Science, Brisbane, QLD, Australia, 7-10 December 2010; pp. 81-88.

18. Kosmala, M.; Wiggins, A.; Swanson, A.; Simmons, B. Assessing data quality in citizen science. Front. Ecol. Environ. 2016, 14, 551-560. [CrossRef]

19. Wiggins, A.; Newman, G.; Stevenson, R.D.; Crowston, K. Mechanisms for data quality and validation in citizen science. In Proceedings of the 2011 IEEE Seventh International Conference on e-Science Workshops, Stockholm, Sweden, 5-8 December 2011; pp. 14-19.

20. Rotman, D.; Hammock, J.; Preece, J.; Hansen, D.; Boston, C.; Bowser, A.; He, Y. Motivations Affecting Initial and Long-Term Participation in Citizen Science Projects in Three Countries. In iConference 2014 Proceedings; iSchools: Incline Village, NV, USA, 2014; pp. 110-124.

21. West, S.; Pateman, R. Recruiting and Retaining Participants in Citizen Science: What Can Be Learned from the Volunteering Literature? Citiz. Sci. Theory Pr. 2016, 1, 15. [CrossRef]

22. Rotman, D.; Preece, J.; Hammock, J.; Procita, K.; Hansen, D.; Parr, C.S.; Lewis, D.; Jacobs, D. Dynamic changes in motivation in collaborative citizen-science projects. In Proceedings of the ACM 2012 Conference on Computer Supported Cooperative Work Companion; Association for Computing Machinery (ACM): New York, NY, USA, 2012; pp. 217-226.

23. Singh, N.J.; Danell, K.; Edenius, L.; Ericsson, G. Tackling the motivation to monitor: Success and sustainability of a participatory monitoring program. Ecol. Soc. 2014, 19, 7. [CrossRef]

24. See, L.; Foody, G.M.; Fritz, S.; Mooney, P.; Olteanu-Raimond, A.-M.; Fonte, C.; Antoniou, V. Motivating and Sustaining Participation in VGI. In Mapping and the Citizen Sensor; Ubiquity Press: London, UK, 2017; pp. 93-117.

25. Hobbs, S.J.; White, P.C.L. Motivations and barriers in relation to community participation in biodiversity recording. J. Nat. Conserv. 2012, 20, 364-373. [CrossRef]

26. Iacovides, I.; Jennett, C.; Cornish-Trestrail, C.; Cox, A.L. Do games attract or sustain engagement in citizen science? In CHI'13 Extended Abstracts on Human Factors in Computing Systems; ACM: New York, NY, USA, 2013; pp. 1101-1106. [CrossRef]

27. Nov, O.; Arazy, O.; Anderson, D. Scientists@Home: What Drives the Quantity and Quality of Online Citizen Science Participation? PLoS ONE 2014, 9, e90375. [CrossRef]

28. Reed, J.; Raddick, M.J.; Lardner, A.; Carney, K. An Exploratory Factor Analysis of Motivations for Participating in Zooniverse, a Collection of Virtual Citizen Science Projects. In Proceedings of the 2013 46th Hawaii International Conference on System Sciences, Wailea, HI, USA, 7-10 January 2013; pp. 610-619.

29. Raddick, M.J.; Bracey, G.; Gay, P.L.; Lintott, C.; Cardamone, C.; Murray, P.; Schawinski, K.; Szalay, A.S.; Vandenberg, J. Galaxy Zoo: Motivations of Citizen Scientists. Astron. Educ. Rev. 2013, 12, 6886. [CrossRef]

30. Curtis, V. Online Citizen Science Projects: An Exploration of Motivation, Contribution and Participation. Ph.D. Thesis, The Open University, Milton Keynes, UK, 2015.

31. Nielsen, J. The 90-9-1 Rule for Participation Inequality in Social Media and Online Communities. Available online: https://www.nngroup.com/articles/participation-inequality/ (accessed on 20 October 2019).

32. Hill, W.C.; Hollan, J.D.; Wroblewski, D.; McCandless, T. Edit wear and read wear. Conf. Hum. Factors Comput. Syst. Proc. 1992, 3-9. [CrossRef]

33. Arthur, C. What Is the $1 \%$ Rule. Available online: https://www.theguardian.com/technology/2006/jul/20/ guardianweeklytechnologysection2 (accessed on 20 October 2019). 
34. Azad, R.; Azad, B.; Khalifa, N.B.; Jamali, S. Real-Time Human-Computer Interaction Based on Face and Hand Gesture Recognition. Int. J. Found. Comput. Sci. Technol. 2014, 4, 37-48. [CrossRef]

35. Budhathoki, N.R. Participants' Motivations to Contribute Geographic Information in an Online Community. Ph.D. Thesis, University of Illinois at Urbana-Champaign, Champaign, IL, USA, 2010.

36. Mooney, P.; Corcoran, P. Characteristics of Heavily Edited Objects in OpenStreetMap. Futur. Internet 2012, 4, 285-305. [CrossRef]

37. Wood, H. The Long Tail of OpenStreetMap. Available online: https://harrywood.co.uk/blog/2014/11/17/thelong-tail-of-openstreetmap/ (accessed on 15 October 2019).

38. OpenStreetMap. OpenStreetMap Stat Report. Retrieved 31 July 2020. Available online: https://wiki. openstreetmap.org/wiki/Stats (accessed on 30 September 2020).

39. Budhathoki, N.R.; Haythornthwaite, C. Motivation for Open Collaboration. Am. Behav. Sci. 2012, 57, 548-575. [CrossRef]

40. Haklay, M.; Capineri, C.; Huang, H.; Antoniou, V.; Kettunen, J.; Ostermann, F.; Purves, R. Why is participation inequality important? Eur. Handb. Crowdsourced Geogr. Inf. 2016, 35-44. [CrossRef]

41. Boakes, E.H.; Gliozzo, G.; Seymour, V.; Harvey, M.; Smith, C.; Roy, D.B.; Haklay, M. Patterns of contribution to citizen science biodiversity projects increase understanding of volunteers' recording behaviour. Sci. Rep. 2016, 6, 33051. [CrossRef] [PubMed]

42. Roy, H.E.; Pocock, M.J.O.; Preston, C.D.; Roy, D.B.; Savage, J.; Tweddle, J.C.; Robinson, L.D. Understanding Citizen Science and Environmental Monitoring. NERC Cent. Ecol. Hydrol. Nat. Hist. Mus. 2012, 1, 1-179.

43. Haklay, M. Volunteered Geographic Information and Citizen Science; SAGE Publishing: New York, NY, USA, 2017; pp. 127-135.

44. Bio Innovation Service. Citizen Science for Environmental Policy: Development of an EU-Wide Inventory and Analysis of Selected Practices; Final report for the European Commission; DG Environment under the contract 070203/2017/768879/ETU/ENV.A.3. In Collaboration with Fundacion I; The Natural History Museum: London, UK, 2018.

45. Wiggins, A.; Crowston, K. From Conservation to Crowdsourcing: A Typology of Citizen Science. In Proceedings of the 2011 44th Hawaii International Conference on System Sciences, Kauai, HI, USA, 4-7 January 2011; pp. 1-10.

46. Storm, P.M. Zooniverse. Choice Rev. Online 2015, 53, 53. [CrossRef]

47. Yadav, P.; Charalampidis, I.; Cohen, J.; Darlington, J.; Grey, F. A Collaborative Citizen Science Platform for Real-Time Volunteer Computing and Games. IEEE Trans. Comput. Soc. Syst. 2018, 5, 9-19. [CrossRef]

48. Westphal, A.J.; Anderson, D.P.; Butterworth, A.; Craig, N. Stardust@home: Virtual Microscope Validation and First Results; LPI: Toronto, AB, Canada, 2006; pp. 1-3.

49. Produit, T.; Ingensand, J. 3D Georeferencing of Historical Photos by Volunteers. Lect. Notes Geoinf. Cartogr. 2018, 12, 113-128. [CrossRef]

50. MacKerron, G.; Mourato, S. Happiness is greater in natural environments. Glob. Environ. Chang. 2013, 23, 992-1000. [CrossRef]

51. Dutta, P.; Aoki, P.M.; Kumar, N.; Mainwaring, A.; Myers, C.; Willett, W.; Woodruff, A. Common Sense. In Proceedings of the 7th ACM Conference on Recommender Systems-RecSys 13; Association for Computing Machinery (ACM): New York, NY, USA, 2009; pp. 349-350.

52. Brovelli, M.A.; Cannata, M.; Rogora, M. Simile, a geospatial enabler of the monitoring of sustainable development goal 6 (ensure availability and sustainability of water for all). ISPRS Int. Arch. Photogramm. Remote. Sens. Spat. Inf. Sci. 2019, 42, 3-10. [CrossRef]

53. Maisonneuve, N.; Stevens, M.; Ochab, B. Participatory noise pollution monitoring using mobile phones. Inf. Polity 2010, 15, 51-71. [CrossRef]

54. Holliman, R.; Curtis, V. Online Media. In Encyclopedia of Science Education; Richard, G., Ed.; Springer: Berlin/Heidelberg, Germany, 2014. [CrossRef]

55. Clary, E.; Snyder, M.; Ridge, R.; Copeland, J.; Stukas, A.; Haugen, J.; Miene, P. Personality Processes and individual differences. Understanding and assessing the motivations of volunteers: A functional approach. J. Pers. Soc. Psychol. 1998, 74, 1516-1530. [CrossRef] [PubMed]

56. Frisch, M.B.; Gerrard, M. Natural helping systems: A survey of Red Cross volunteers. Am. J. Community Psychol. 1981, 9, 567-579. [CrossRef] 
57. Batson, C.D.; Ahmad, N.Y.; Tsang, J.-A. Four Motives for Community Involvement. J. Soc. Issues 2002, 58, 429-445. [CrossRef]

58. Ryan, R.M.; Deci, E.L. Intrinsic and Extrinsic Motivations: Classic Definitions and New Directions. Contemp. Educ. Psychol. 2000, 25, 54-67. [CrossRef] [PubMed]

59. Hossain, M. Users' motivation to participate in online crowdsourcing platforms. In Proceedings of the 2012 International Conference on Innovation Management and Technology Research, Malacca, Malaysia, 21-22 May 2012; pp. 310-315. [CrossRef]

60. Tinati, R.; Luczak-Roesch, M.; Simperl, E.; Hall, W. An investigation of player motivations in Eyewire, a gamified citizen science project. Comput. Hum. Behav. 2017, 73, 527-540. [CrossRef]

61. Curtis, V. Motivation to Participate in an Online Citizen Science Game. Sci. Commun. 2015, 37, 723-746. [CrossRef]

62. Lakhani, K.; Wolf, R.G. Why Hackers Do What They Do: Understanding Motivation and Effort in Free/Open Source Software Projects. In Perspectives on Free and Open Source Software; MIT Press: Cambridge, MA, USA, 2007; pp. 3-21.

63. Hars, S.O.A. Working for Free? Motivations for Participating in Open-Source Projects. Int. J. Electron. Commer. 2002, 6, 25-39. [CrossRef]

64. OpenStreetMap. How To Contribute? 2018. Available online: https://wiki.openstreetmap.org/wiki/How_to_ contribute (accessed on 30 September 2020).

65. Coetzee, S.; Minghini, M.; Solís, P.; Rautenbach, V.; Green, C. Towards understanding the impact of mapathons-Reflecting on youthmappers experiences. ISPRS Int. Arch. Photogramm. Remote. Sens. Spat. Inf. Sci. 2018, 42, 35-42. [CrossRef]

66. Quill, T. Humanitarian Mapping as Library Outreach: A Case for Community-Oriented Mapathons. J. Web. Libr. 2018, 12, 160-168. [CrossRef]

67. Kamptner, E.; Kessler, F. Small-scale crisis response mapping: Comparing user contributions to events in OpenStreetMap. GeoJournal 2019, 84, 1165-1185. [CrossRef]

68. Hristova, D.; Quattrone, G.; Mashhadi, A.; Capra, L. The Life of the Party: Impact of Social Mapping in OpenStreetMap; ICWSM: Atlanta, GA, USA, 2013; pp. 234-243.

69. Khanal, K.; Budhathoki, N.R.; Erbstein, N. Filling OpenStreetMap data gaps in rural Nepal: A digital youth internship and leadership Programme. Open Geospat. Data Softw. Stand. 2019, 4, 1-10. [CrossRef]

70. Johnson, B.A. How an augmented reality game (Pokémon GO) affected volunteer contributions to OpenStreetMap. Proc. ICA 2019, 2, 1-4. [CrossRef]

71. Green, C.; Rautenbach, V.; Coetzee, S. Evaluating student motivation and productivity during mapathons. ISPRS Int. Arch. Photogramm. Remote. Sens. Spat. Inf. Sci. 2019, 42, 85-91. [CrossRef]

72. OpenStreetMap. Gamification. 2013. Available online: https://wiki.openstreetmap.org/wiki/Gamification (accessed on 30 September 2020).

73. Ganzevoort, W.; Born, R.J.G.V.D.; Halffman, W.; Turnhout, S. Sharing biodiversity data: Citizen scientists' concerns and motivations. Biodivers. Conserv. 2017, 26, 2821-2837. [CrossRef]

74. Domroese, M.C.; Johnson, E.A. Why watch bees? Motivations of citizen science volunteers in the Great Pollinator Project. Biol. Conserv. 2017, 208, 40-47. [CrossRef]

75. Alender, B. Understanding volunteer motivations to participate in citizen science projects: A deeper look at water quality monitoring. J. Sci. Commun. 2016, 15, A04. [CrossRef]

76. Anderson, D.; Cobb, J.; Korpela, E.; Lebofsky, M. SETI@home. Commun. ACH. 2002, 45, 56-61. [CrossRef]

77. Beberg, A.L.; Ensign, D.L.; Jayachandran, G.; Khaliq, S.; Pande, V.S. Folding@home: Lessons from eight years of volunteer distributed computing. In Proceedings of the 2009 IEEE International Symposium on Parallel \& Distributed Processing, Rome, Italy, 23-29 May 2009; pp. 1-8.

78. Cooper, S.; Khatib, F.; Treuille, A.; Barbero, J.; Lee, J.; Beenen, M.; Leaver-Fay, A.; Baker, D.; Popović, Z.; Players, F. Predicting protein structures with a multiplayer online game. Nat. Cell Biol. 2010, 466, 756-760. [CrossRef]

79. Atkinson, J.W. Motivational Determinants of Risk-Taking Behavior. Psychol. Rev. 1957, 64, 359. [CrossRef]

80. Nov, O.; Arazy, O.; Anderson, D. Dusting for Science: Motivation and Participation of Digital Citizen Science Volunteers. In Proceedings of the 2011 iConference; ACM: Seattle, WA, USA, 2011; pp. 68-74. [CrossRef] 
81. Nov, O.; Anderson, D.; Arazy, O. Volunteer Computing: A Model of the Factors Determining Contribution to Community-Based Scientific Research. In Proceedings of the 19th International Conference on Distributed Computing and Networking, Raleigh, NC, USA, 26-30 April 2010; pp. 741-750.

82. Curtis, V. Patterns of Participation and Motivation in Folding@home: The Contribution of Hardware Enthusiasts and Overclockers. Citiz. Sci. Theory Pr. 2018, 3, 1-4. [CrossRef]

83. Lotfian, M.; Ingensand, J.; Ertz, O.; Composto, S.; Oberson, M.; Oulevay, S.; Campisi, D.; Joerin, F. Participants' motivations to contribute to biodiversity citizen science projects. Peer] 2018, 6. [CrossRef]

84. Kirch, W. (Ed.) Pearson's Correlation Coefficient. In Encyclopedia of Public Health; Springer: Dordrecht, The Netherlands, 2008; pp. 1090-1091.

85. Olsson, U.; Drasgow, F.; Dorans, N.J. The polyserial correlation coefficient. Psychometrika 1982, 47, 337-347. [CrossRef]

86. Buck, J.L.; Finner, S.L. A still further note on freeman's measure of association. Psychometrika 1985, 50, 365-366. [CrossRef]

87. Mize, A. Expanding the Reach of Environmental Research with Citizen Science. Available online: https://www. esa.org/blog/2015/09/30/expanding-the-reach-of-environmental-research-with-citizen-science/ (accessed on 15 June 2018).

88. Ingensand, J.; Lotfian, M.; Composto, S.; Ertz, O.; Oulevay, S.; Oberson, M.; Da Cunha, M.; Piot, D. Augmented reality technologies for biodiversity education-A case study. In Proceedings of the 21st Conference on Geo-Information Science, AGILE 2018, Lund, Sweden, 12-15 June 2018.

89. Lotfian, M.; Ingensand, J.; Ertz, O.; Oulevay, S.; Chassin, T. Auto-filtering validation in citizen science biodiversity monitoring: A case study. Proc. ICA 2019, 2, 1-5. [CrossRef]

Publisher's Note: MDPI stays neutral with regard to jurisdictional claims in published maps and institutional affiliations. 